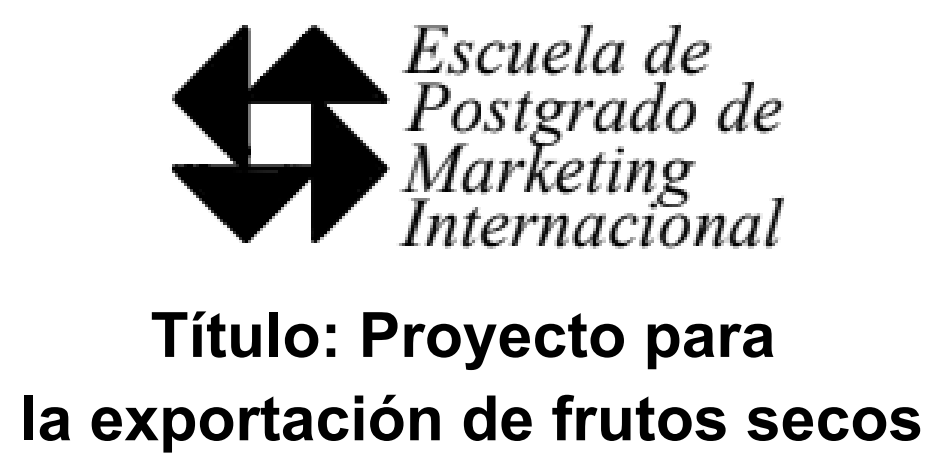

Trabajo Científico libre para la obtención del grado de

Magister en Marketing Internacional de la Escuela de Postgrado de Marketing Internacional

Facultad de Ciencias Económicas

- Universidad Nacional de La Plata -

Profesor Director de Tesis:

Presentado por:

Dra. Cristina Zapata

Gheraldine Mancilla Toro

Beruti 4441, CABA

Fecha de entrega: 6 de marzo de 2020 
"Solo las personas que se atreven a ir demasiado lejos,

logran descubrir hasta donde pueden llegar".

T.S. Eliot.

La idea que surgió en un viaje de tren hoy se materializa.

El sueño que me trajo a este país tan lejos de mi Barranquilla, hoy vale la pena.

Quiero agradecer a todos los que de una u otra forma contribuyeron con su granito de arena a la escritura de esta tesis.

Al Creador, por conspirar a favor de los sueños.

Al amor de mi vida, por darme soporte y apoyo cada vez que lo necesité.

A mi directora de tesis, Dra. Cristina Zapata, ya que gracias a su incansable búsqueda de

la perfección, pude dar lo mejor de mi para el desarrollo de este proyecto.

A mis padres y a mi hermanita, que desde la distancia me brindaron su apoyo.

A mis amigos, que siempre los sentí tan cercanos.

Las líneas escritas a continuación son fruto de esfuerzo, paciencia y mucho aprendizaje. 


\section{PROYECTO PARA LA EXPORTACIÓN DE FRUTOS SECOS}

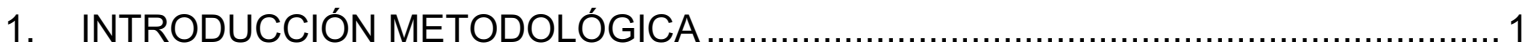

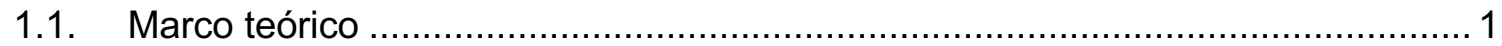

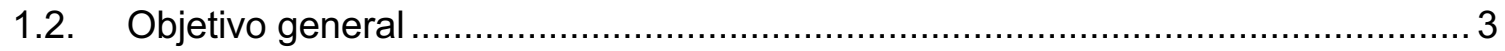

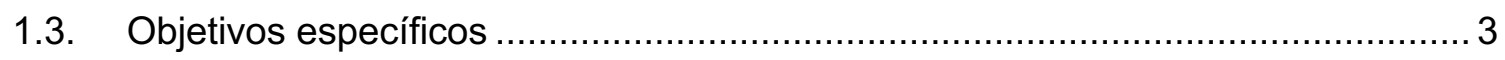

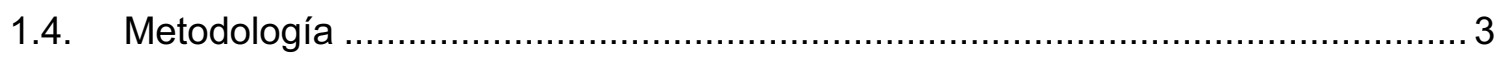

2. LA PRODUCCIÓN ARGENTINA DE FRUTOS SECOS Y SU POTENCIAL

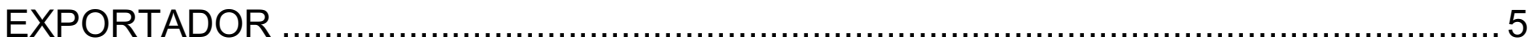

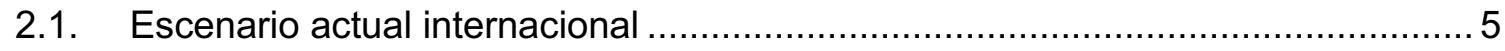

2.2. Producción de frutos secos en Argentina ....................................................... 7

2.3. Producción de Almendra en Argentina ......................................................... 8

2.4. Producción de Avellana en Argentina ................................................................. 11

2.5. Producción de Castaña en Argentina .......................................................... 13

2.6. Producción de Castaña de Cajú en Argentina ................................................. 15

2.7. Producción de Castaña o Nuez de Pará, nuez de Brasil o Bacurí en Argentina 17

2.8. Producción de Nuez Nogal en Argentina ................................................... 18

2.9. Producción de Nuez Pecán en Argentina ........................................................ 21

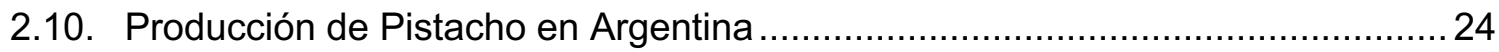

2.11. Potencial exportador de frutos secos argentinos al mercado internacional ........27

3. ASPECTOS RELEVANTES PARA LA EXPORTACIÓN DE FRUTOS SECOS AL

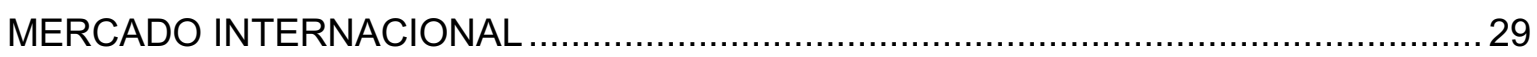

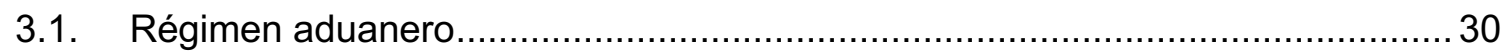

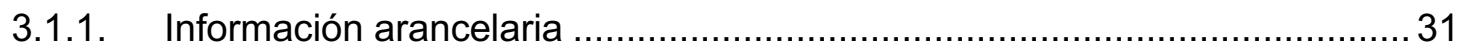

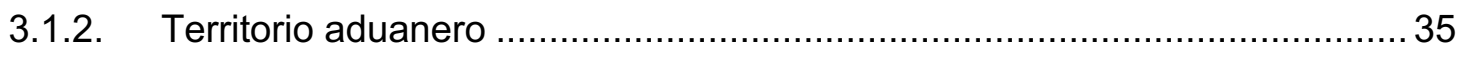

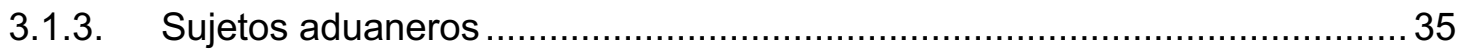




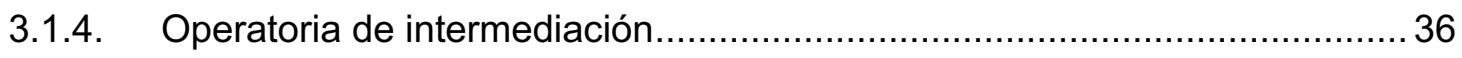

3.1.5. Certificado Comercial para la exportación de frutos secos en Argentina .... 36

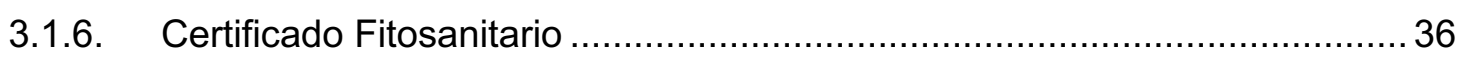

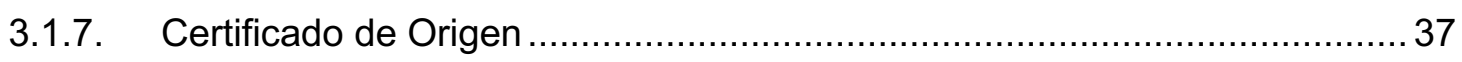

3.1.8. Visto Bueno de Importación para la importación de frutos secos en

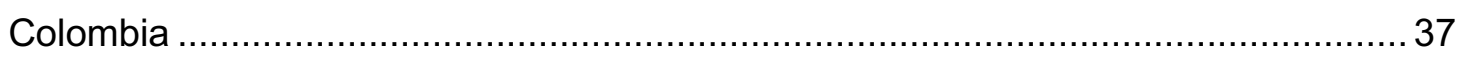

3.1.9. Métodos de valoración aduanera....................................................... 38

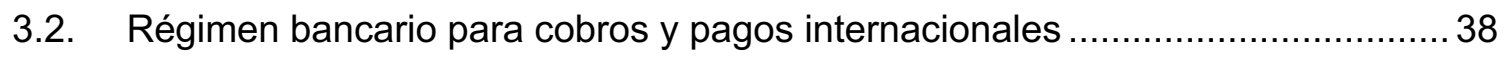

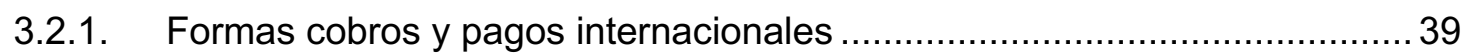

3.2.2. Bancos argentinos con corresponsalía en el exterior ................................ 40

3.2.3. Financiamiento y tipo de cambio .................................................... 40

3.3. Transporte internacional de carga ......................................................... 41

3.3.1. Empacado y envasado de frutos secos para la exportación .......................41

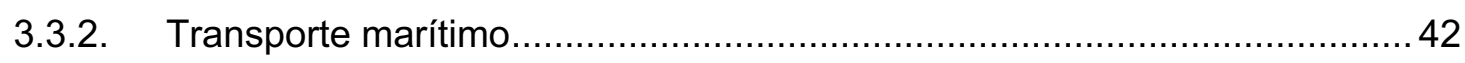

3.3.2.1. Características de carga marítima habitual para frutos secos ................. 43

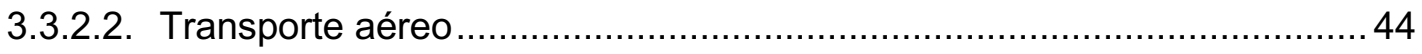

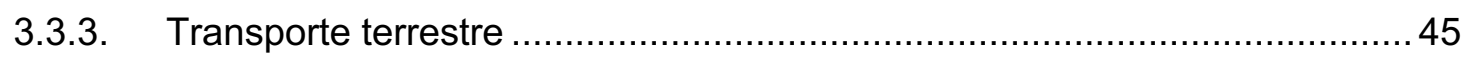

3.3.4. Transporte marítimo desde Chile.................................................... 46

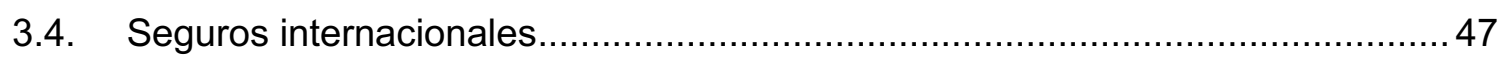

3.5. Documentación de embarque habitual para la exportación de frutos secos ......48

3.5.1. Documentación requerida para exportar desde Argentina(fuente)..............48 48

3.5.2. Documentación requerida para importar en Colombia .............................. 48

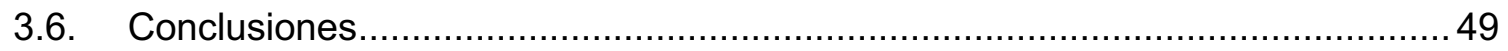

4. PARÁMETROS DEL PROYECTO DE EXPORTACIÓN DE FRUTOS SECOS ........51

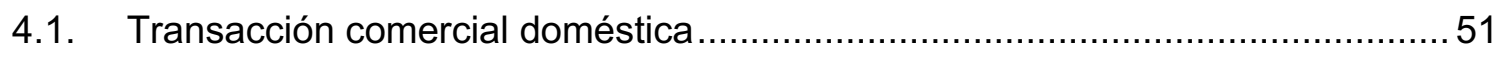

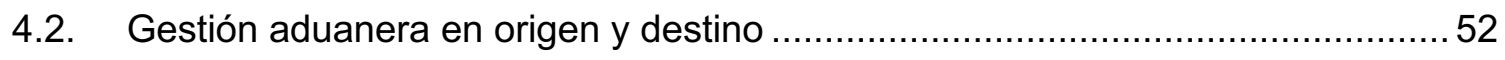

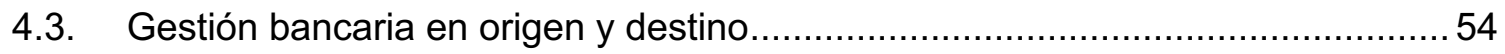

4.4. Tránsito doméstico de la mercadería desde origen hasta el puerto de

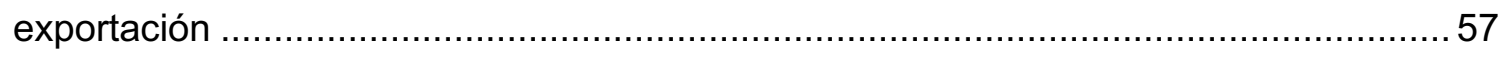

4.5. Acondicionamiento y consolidación de la carga para la exportación...................57

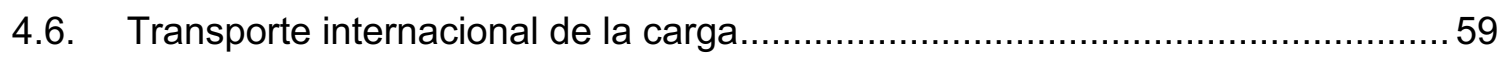


4.7. Documentación de embarque con las certificaciones necesarias en origen y destino

4.7.1. Documentación de embarque y certificaciones requeridas para exportar desde Argentina

4.7.2. Documentos y certificaciones requeridas para importar en Colombia.

4.8. Costos

4.8.1. Cálculo de costos operativos de exportación (averiguar bien si está gravada por el impuesto)......

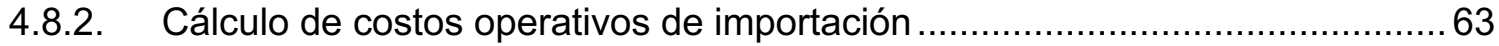

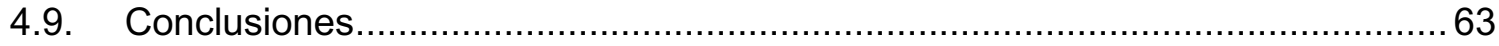

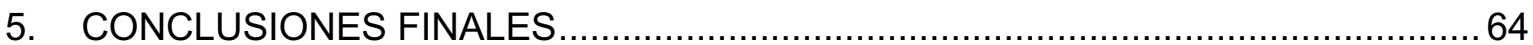

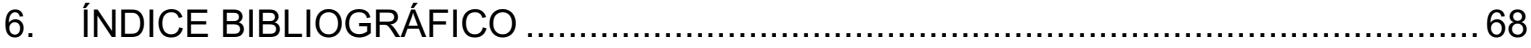

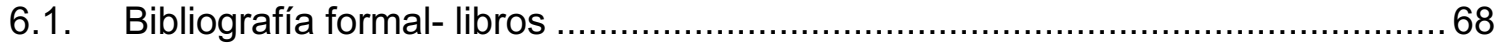

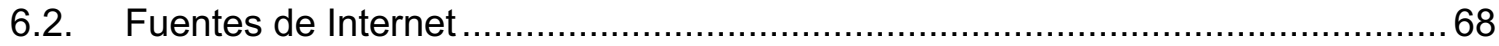


Índice de tablas

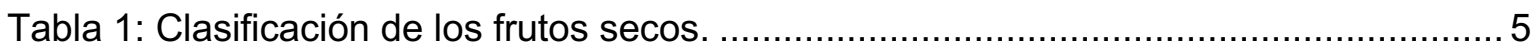

Tabla 2: Exportaciones de almendras. 2013-2017 ..................................................... 10

Tabla 3: Importaciones de almendras. 2013-2017...................................................... 10

Tabla 4: Exportaciones de avellanas 2013-2017. ......................................................... 13

Tabla 5: Importaciones de avellanas 2013-2017......................................................... 13

Tabla 6: Importaciones de castañas de cajú. 2013-2017............................................ 16

Tabla 7: Importaciones de nueces de Brasil. 2013-2017. ............................................ 18

Tabla 8: Exportaciones de nuez nogal. 2013-2017 ................................................... 20

Tabla 9: Exportaciones de nuez nogal. 2013-2017 ..................................................... 21

Tabla 10: Exportaciones de nuez pecán 2013-2017................................................... 23

Tabla 11: Importaciones de nuez pecán. 2013-2017 ..................................................... 24

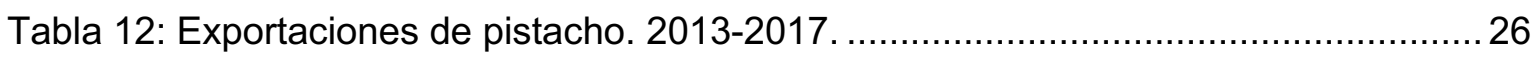

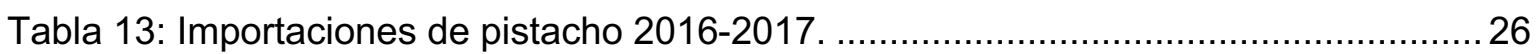

Tabla 14: Información aduanera de nueces de nogal sin cáscara en Argentina y

Colombia.

Tabla 15: Información aduanera de nueces de pecán sin cáscara en Argentina y

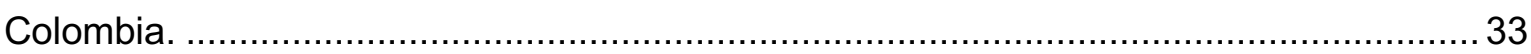

Tabla 16: Información aduanera de pistachos con cáscara en Argentina y Colombia...... 34

Tabla 17: Bancos autorizados para operar en comercio exterior en Argentina y en

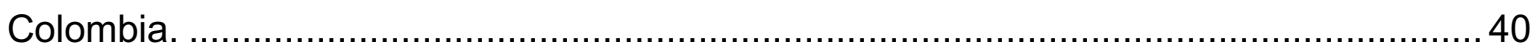

Tabla 18: Empresas navieras que cubren la ruta Argentina- Colombia.......................... 43

Tabla 19: Aerolíneas que cubren la ruta Argentina- Colombia........................................ 45

Tabla 20: Información arancelaria de nueces de nogal sin cáscara, nueces de pecán sin

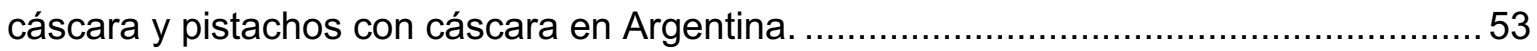

Tabla 21: Costos aduaneros en Argentina y en Colombia............................................. 54

Tabla 22: Comisiones de comercio exterior en Argentina................................................. 55

Tabla 23: Comisiones de comercio exterior en Colombia.................................................. 56

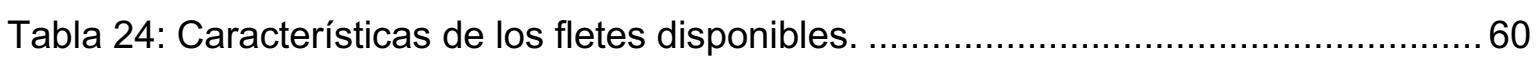

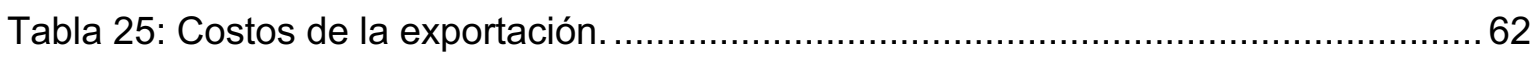

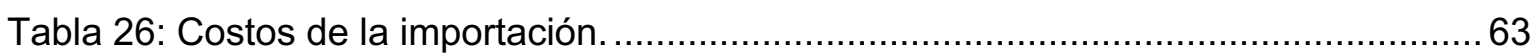


Índice de esquemas

Esquema 1: Producción de frutos secos en toneladas por países.2018/2019................. 6

Esquema 2: Hectáreas cultivadas de frutos secos en Argentina. 2017 .......................... 7

Esquema 3: Hectáreas cultivadas por especie de frutos seco en Argentina. 2017. .......... 7

Esquema 4: Superficie de almendras cultivada en hectáreas. 2017 ................................ 8

Esquema 5: Producción argentina de almendras en toneladas. ................................... 9

Esquema 6: Producción media de almendras en toneladas por países. 2013-2017. ........ 9

Esquema 7: Superficie de avellanas cultivada en hectáreas. 2017............................. 11

Esquema 8: Producción media de avellanas en toneladas por países. 2013-2017.......... 12

Esquema 9: Superficie de castaña cultivada en hectáreas. 2017 ............................... 14

Esquema 10: Producción media de castañas en toneladas por países. 2013-2017........ 15

Esquema 11: Producción media de castañas de cajú en toneladas por países. 2013-

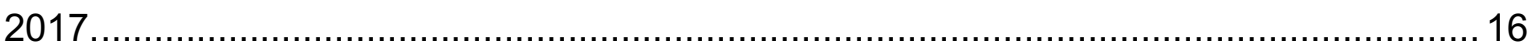

Esquema 12: Producción media de nueces de Brasil en toneladas por países. 2013-2017.

Esquema 13: Superficie de nuez nogal cultivada en hectáreas. 2017 .......................... 19

Esquema 14: Producción argentina de nuez nogal en toneladas. 2013- 2017............... 19

Esquema 15: Producción media de nuez nogal en toneladas por países. 2013-2017. ... 20

Esquema 16: Superficie de nuez pecán cultivada en hectáreas. 2017 ........................... 22

Esquema 17: Producción media de nuez pecán en toneladas por países. 2013-2017 ... 23

Esquema 18: Superficie de pistacho cultivada en hectáreas. 2017.............................. 25

Esquema 19: Producción media de pistacho en toneladas por países. 2013-2017.......... 25

Esquema 20: Cronograma del primer embarque para el proyecto exportador. ................66

Esquema 21: Cronograma de los embarques para el primer año del proyecto exportador. 
Índice de ilustraciones

Ilustración 1: Modelo de bolsa para el empacado de los frutos secos. ............................58

Ilustración 2: Simulación de la ubicación de la carga en el pallet. ...................................58 


\section{INTRODUCCIÓN METODOLÓGICA}

\subsection{Marco teórico}

En un mundo globalizado como el actual, las empresas se ven en la imperiosa necesidad de innovar, pensar estratégicamente y conquistar nuevos mercados. De acuerdo con Sainz de Vicuña Ancin ${ }^{1}$, existen tres dimensiones clave para redefinir el negocio: nuevos servicios, nuevos clientes y nuevas tecnologías. En ese proyecto nos ocuparemos del proceso de conquistar nuevos clientes con el ingreso a nuevos mercados a través de la exportación de productos.

Según Bradley ${ }^{2}$ los intercambios entre países nacen como consecuencia de la existencia de una ventaja absoluta o comparativa para el comercio. Así, dos países con especializaciones distintas del mismo producto, uno en la producción y otro en la fabricación, comercializan entre sí generando un beneficio para ambos. La comercialización internacional nace a partir de este intercambio.

De acuerdo con Cignacco $^{3}$ la internacionalización de una empresa significa una gradual y constante asunción de compromisos de distinta índole, que permite una progresiva conexión con los mercados externos, tanto desde el punto de vista de operaciones de exportación, como de importación. Por otro lado, Sainz de Vicuña Ancin ${ }^{1}$ afirma que internacionalización es un proceso en el que nuestra empresa se convierte en un importante actor internacional o global, en su mercado relevante, siendo la exportación sólo un conjunto de transacciones comerciales con agentes de otros mercados.

Continuando con Cignacco ${ }^{4}$ una empresa se puede internacionalizar de diversas formas: vía exportación, mediante la producción total o parcial en destino o a través de otras formas llamadas mixtas o no tradicionales (licencias, franquicias, contrato de

\footnotetext{
${ }^{1}$ Sainz de Vicuña Ancin, J.M. (2016). Plan de internacionalización de la pyme en la práctica. Madrid: Esic

${ }^{2}$ Bradley, F. Y Haydeé, C. (2006). Marketing Internacional 5a edición. Pearson: Buenos Aires

${ }^{3}$ Cignacco, B. (2004). Fundamentos de comercialización internacional para pymes. (c.6 pp.207)Buenos Aires: Macchi

${ }^{4}$ Cignacco, B. (2004). Fundamentos de comercialización internacional para pymes.(c.6 pp.205)Buenos Aires: Macchi
} 
manufactura, etc. ). En consecuencia a lo anterior, la exportación se constituye como un paso fundamental en el proceso de internacionalización de una empresa.

Kotler ${ }^{5}$ afirma que la forma más sencilla para ingresar a un mercado extranjero es a través de la exportación, ya que implica el menor cambio posible en las líneas de producto, la organización, las inversiones o la misión de la empresa. Al ingresar a un mercado internacional se deben tener en cuenta ciertas variables que permitan diseñar una estrategia que minimice el riesgo que conlleva la exploración de nuevos horizontes comerciales.

La estrategia de comercialización internacional comprende una serie de pasos que permiten evaluar la viabilidad de ingresar el producto al mercado elegido a través de la exportación.

De acuerdo con Campana ${ }^{6}$ el empresario que pretenda incursionar con éxito en el campo de comercio internacional, debe prestar un servicio adecuado y manejar una línea de conducta que le permita ser competitivo en un mercado desconocido y a veces, hostil.

Continuando con Campana ${ }^{7}$ para llevar a cabo un proyecto de comercio internacional exitoso, se requiere una estructura que incluya:

- Análisis de la capacidad actual de la firma

- Análisis de sus posibilidades de crecimiento

- Estudio profundo del mercado que se quiere incursionar

- Posibilidades de participación competitiva en dicho mercado

- Concreción de contactos con eventuales contrapartes

- Programa del viaje con agenda formal al mercado elegido

- Consideración del envío de muestras

- Presupuesto operativo bien definido.

Sumado a lo anterior, se deberá evaluar las políticas aduaneras del país destino y coordinar el aspecto logístico de la comercialización internacional. Así las cosas, la

\footnotetext{
${ }^{5}$ Kotler, P. Y Amstrong, G. (2017). Marketing 17a edición. Ciudad de México: Pearson Educación

${ }^{6}$ Campana, E. (2001). El desafío de exportar: una visión clara y renovadora de las herramientas básicas para conquistar los mercados internacionales.(c.2 pp.10) Macchi: Buenos Aires

${ }^{7}$ Campana, E. (2001). El desafío de exportar: una visión clara y renovadora de las herramientas básicas para conquistar los mercados internacionales.(c.4 pp.72) Macchi: Buenos Aires
} 
exportación se define como el primer paso en el proceso de internacionalización de una empresa y se fundamenta en una estructura que permita llevar a cabo un camino exitoso hacia los nuevos mercados.

\subsection{Objetivo general}

Desarrollar un proyecto estratégico para la exportación de frutos secos: almendras, nueces y pistachos desde Argentina al mercado internacional.

\subsection{Objetivos específicos}

- Estudiar la producción argentina de frutos secos y su potencial exportador.

- Identificar los aspectos relevantes para la exportación de frutos secos en el mercado a incursionar.

- Establecer los lineamientos para llevar a cabo el plan exportador.

\subsection{Metodología}

La delimitación temporal de este proyecto de tesis es actual, ya que en base a datos e información actualizada sobre el sector de frutos secos en Argentina se diseñará un plan de exportación internacional.

La delimitación geográfica de este proyecto de tesis es internacional, porque abarca un tema que involucra la exportación de un producto entre dos países.

Para el desarrollo de este proyecto estratégico se utilizarán métodos de recolección de datos tanto cualitativos, como cuantitativos. Los datos cualitativos servirán para conocer información de la logística y el mercado. Los datos cuantitativos serán útiles para comprender el contexto actual del sector productivo de frutos secos en Argentina.

Se hará uso de fuentes primarias y secundarias. Las fuentes primarias comprenderán entrevistas a profundidad con expertos en el sector económico que enmarca el proyecto, 
para estudiar detalles del producto, logística y mercado que puedan incidir en el desarrollo de los lineamientos del plan estratégico de exportación internacional.

Las fuentes secundarias comprenderán la recopilación de material de consulta vía Internet de organismos de estadística oficial y otras organizaciones especializadas en el tema, con el fin de estudiar el panorama actual de la producción argentina de frutos secos y evaluar su viabilidad exportadora.

La captación de datos en las entrevistas a profundidad se hará a través de una muestra con preguntas semiestructuradas, que permita propiciar una conversación con el entrevistado donde sea posible obtener información valiosa adicional.

En consecuencia a lo anterior, este proyecto de tesis corresponde al desarrollo de una investigación de tipo exploratoria, ya que se hará un estudio del escenario externo de la producción de frutos secos argentina para luego elaborar un proyecto estratégico de exportación a nivel internacional. 


\section{LA PRODUCCIÓN ARGENTINA DE FRUTOS SECOS Y SU POTENCIAL EXPORTADOR}

\subsection{Escenario actual internacional}

Se denominan frutos $\operatorname{secos}^{8}$ a los que en su estado natural de maduración presentan un contenido de humedad que permite conservarlos sin necesidad de someterlos a un tratamiento especial. Poseen un endocarpio más o menos lignificado, y la parte comestible es la semilla. El Código Alimentario Argentino (CAA) detalla así los frutos secos comestibles:

\begin{tabular}{|l|l|}
\hline Nombre común & Nombre taxonómico \\
\hline Almendra & $\begin{array}{l}\text { Prunus dulcis (Mill.) D.A. Webb syn. Prunus } \\
\text { amygdalus Batsch }\end{array}$ \\
\hline Avellana & Corylus avellana L. \\
\hline Castaña & Castanea sativa Mill. \\
\hline Castaña de cajú & Anacardium occidentale L. \\
\hline Castaña o Nuez de Pará, nuez de Brasil o & $\begin{array}{l}\text { Bertholletia excelsa Humb. \& Bonpl. (sin. } \\
\text { Bertholletia nobilis Miers.) }\end{array}$ \\
\hline Nuez Nogal & Juglans regia L. \\
\hline Nuez Pecán & Carya illinoinensis (Wangenh) K. Koch. \\
\hline Pistacho & Pistacia vera L. \\
\hline
\end{tabular}

Tabla 1: Clasificación de los frutos secos.

Fuente: Anmat- Código Alimentario ${ }^{9}$

\footnotetext{
${ }^{8}$ Código Alimentario Argentino, Capítulo XI. Recuperado de https://www.argentina.gob.ar/anmat/codigoalimentario Información tomada el 20 de agosto de 2019

${ }^{9}$ Código Alimentario Argentino, Recuperado de https://www.argentina.gob.ar/sites/default/files/capitulo xi vegetales actualiz 2019-6 .pdf Información tomada el 22 de agosto de 2019.
} 
Según datos del Consejo Internacional de Frutos Secos $(\text { INC })^{10}$ en la temporada 2018/2019 la producción mundial de nueces (almendras, nueces, castañas de cajú, pistachos, avellanas, nueces pecanas, macadamias, piñones y nueces de Brasil) llegó a 4,5 millones de toneladas métricas, lo que representa un incremento general del $47 \%$ en comparación a 10 años atrás. Los mayores aumentos de cosechas en 2018/19 fueron registrados para macadamias $(57 \%)$, pistachos $(43 \%)$, nueces $(37 \%)$ y castañas de cajú (32\%), en comparación con el promedio de 10 años atrás.

Estados Unidos ${ }^{11}$ lidera la producción mundial de frutos secos. En 2018/2019 representó el $41 \%$ de participación mundial, siendo las almendras, los pistachos y las nueces los principales cultivos, seguido de Turquía (12\%) y China (8\%).

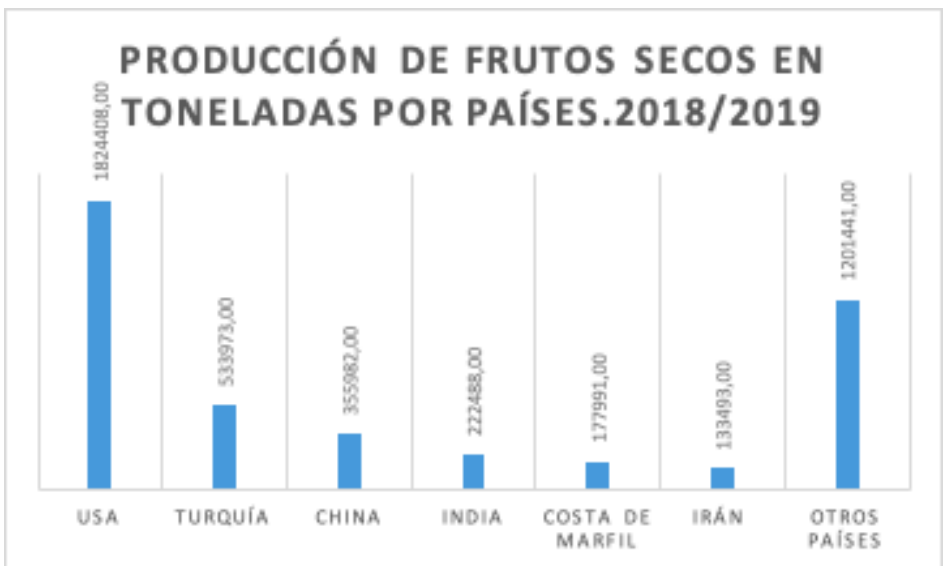

Esquema 1: Producción de frutos secos en toneladas por países.2018/2019.

Fuente: Elaboración propia basada en datos de referencia ${ }^{12}$

La producción de frutos secos brinda una nueva oportunidad de cultivos con tendencia al alza para los países que cuentan con las condiciones agro climáticas idóneas, ya que cada especie en particular requiere sus propias especificaciones tanto técnicas, como ambientales.

\footnotetext{
10 International Nut \& Dried Fruit Council (INC). Recuperado de: https://www. nutfruit.org/industry/technicalresources?category=statistical-yearbooks Información tomada el 16 de octubre de 2019

${ }^{11}$ International Nut \& Dried Fruit Council (INC). Recuperado de: https://www. nutfruit.org/industry/technicalresources?category=statistical-yearbooks Información tomada el 17 de octubre de 2019

12 International Nut \& Dried Fruit Council (INC). Recuperado de: https://www. nutfruit.org/industry/technicalresources?category=statistical-yearbooks Información tomada el 17 de octubre de 2019
} 


\subsection{Producción de frutos secos en Argentina}

Según el último Relevamiento Nacional de Frutos $\operatorname{Secos}^{13}$, con datos actualizados al año 2017, en Argentina hay un total de 23.204 hectáreas cultivadas. A continuación la distribución de hectáreas por provincia y las hectáreas por cada especie en el territorio argentino.

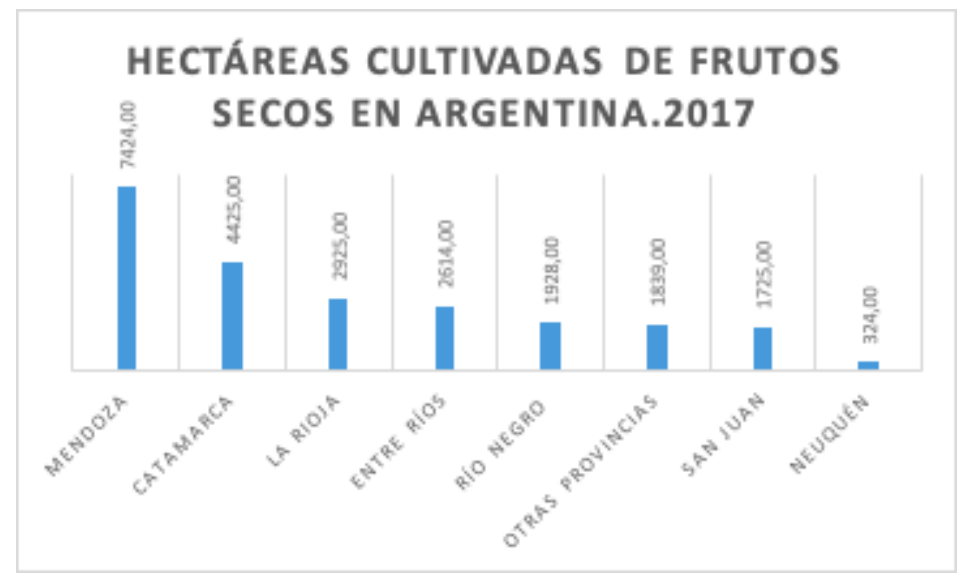

Esquema 2: Hectáreas cultivadas de frutos secos en Argentina. 2017.

Fuente: Elaboración propia basada en datos de referencia ${ }^{14}$

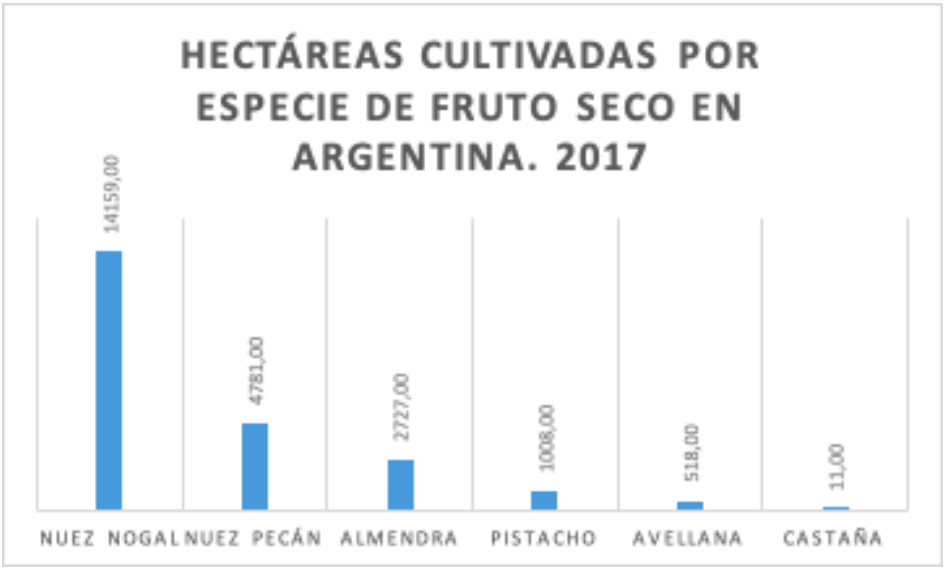

Esquema 3: Hectáreas cultivadas por especie de frutos seco en Argentina. 2017.

Fuente: Elaboración propia basada en datos de referencia ${ }^{15}$

\footnotetext{
${ }^{13}$ Relevamiento Nacional de Frutos Secos. Universidad de Cuyo: https://app.powerbi.com/view?r=eyJrljoiNWRkYmFIZjgtNzU4ZS00ZGQzLWJkNzYtNjigyNDI3NWM3YTU3liwidCI6ImZmNjdk ZTc3LWRjN2YtNGRIZC1iNjA3LWM4MDhkNWI4Zjk2MilsImMiOjR9 Información tomada el 17 de octubre de 2019.

${ }^{14}$ Relevamiento Nacional de Frutos Secos. Universidad de Cuyo: https://app.powerbi.com/view?r=eyJrljoiNWRkYmFIZjgtNzU4ZS00ZGQZLWJkNzYtNjgyNDI3NWM3YTU3liwidCI6ImZmNidk ZTc3LWRjN2YtNGRIZC1iNjA3LWM4MDhkNWI4Zjk2MilsImMiOjR9 Información tomada el 20 de octubre de 2019.

${ }^{15}$ Relevamiento Nacional de Frutos Secos. Universidad de Cuyo:

https://app.powerbi.com/view?r=eyJrljoiNWRkYmFIZjgtNzU4ZS00ZGQzLWJkNzYtNjigyNDI3NWM3YTU3liwidCI6ImZmNjdk ZTc3LWRjN2YtNGRIZC1iNjA3LWM4MDhkNWI4Zjk2MilsImMiOjR9 Información tomada el 20 de octubre de 2019.
} 


\subsection{Producción de Almendra en Argentina}

Se conoce como almendra ${ }^{16}$ la fruta seca obtenida de Prunus amygdalus (Batsch), las principales variedades en el territorio argentino comprenden la Nonpareil y Guara, seguidas de otros tipos de menor importancia como la Marinada, Emilito INTA y Felizia.

Las variedades analizadas son la Nonpareil, de cáscara blanda, ligeramente alargadas y gruesas; y la Guara, que se caracteriza por poseer una cáscara dura y tamaño medio.

La almendra se comercializa en 4 presentaciones diferentes: (1) con cáscara; (2) pelada (descascarada): entera, fileteada y molida; (3) blanqueada (repelada): entera, fileteada, molida y en harina; y (4) en aceite. Argentina comercializa almendras con cáscara y sin cáscara. De la cosecha $2017^{17}$, el porcentaje de almendra con cáscara comercializada correspondió al $37 \%$ y de almendra sin cáscara el $63 \%$.

Según datos del INTA ${ }^{18}$ el cultivo del almendro se adapta bien a condiciones climáticas de alta radiación solar, extrema sequía ambiental y altas temperaturas, similares a las de la región argentina, siendo las heladas primaverales el factor de mayor riesgo en la pérdida de cultivos.

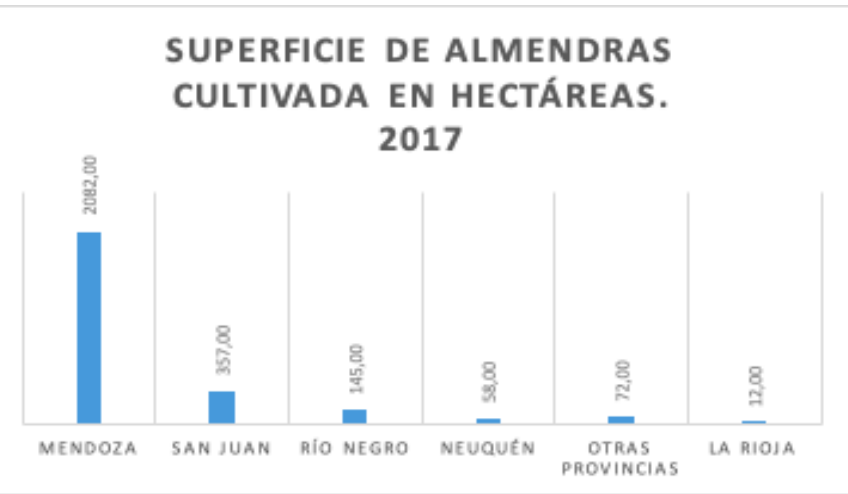

Esquema 4: Superficie de almendras cultivada en hectáreas. 2017.

Fuente: Elaboración propia basada en datos de referencia ${ }^{19}$

\footnotetext{
${ }^{16}$ Alimentos Argentinos. Recuperado de:

http://www.alimentosargentinos.gob.ar/HomeAlimentos/Frutas\%20secas/frutasecas/productos/Almendras 2003/Almendras. htm Información tomada el 20 de octubre de 2019.

17 Alimentos Argentinos. Recuperado de:

http://www.alimentosargentinos.gob.ar/HomeAlimentos/Frutas\%20secas/frutasecas/productos/Almendras_2003/Almendras. htm Información tomada el 20 de noviembre de 2019.

18 INTA. Recuperado de:https://inta.gob.ar/noticias/almendros-las-ventajas-que-ofrece-este-cultivo-y-los-cuidados-querequiere Información tomada el 23 de octubre de 2019.

${ }^{19}$ Relevamiento Nacional de Frutos Secos. Universidad de Cuyo:

https://app.powerbi.com/view?r=eyJrljoiNWRkYmFIZjgtNzU4ZS00ZGQzLWJkNzYtNjgyNDI3NWM3YTU3liwidCI6ImZmNjdk ZTc3LWRjN2YtNGRIZC1iNjA3LWM4MDhkNWI4Zjk2MilsImMiOjR9 Información tomada el 20 de octubre de 2019
} 
En el territorio argentino, Mendoza y San Juan concentran alrededor del $90 \%$ de los cultivos de almendra y por ende, son las dos provincias con mayor cantidad de producción a nivel nacional.

Según información actualizada por la $\mathrm{FAO}^{20}$ al año 2017, Argentina ocupa el puesto no. 35 a nivel mundial en producción de almendras con cáscara, con un crecimiento del $8 \%$ entre 2013 y 2017.

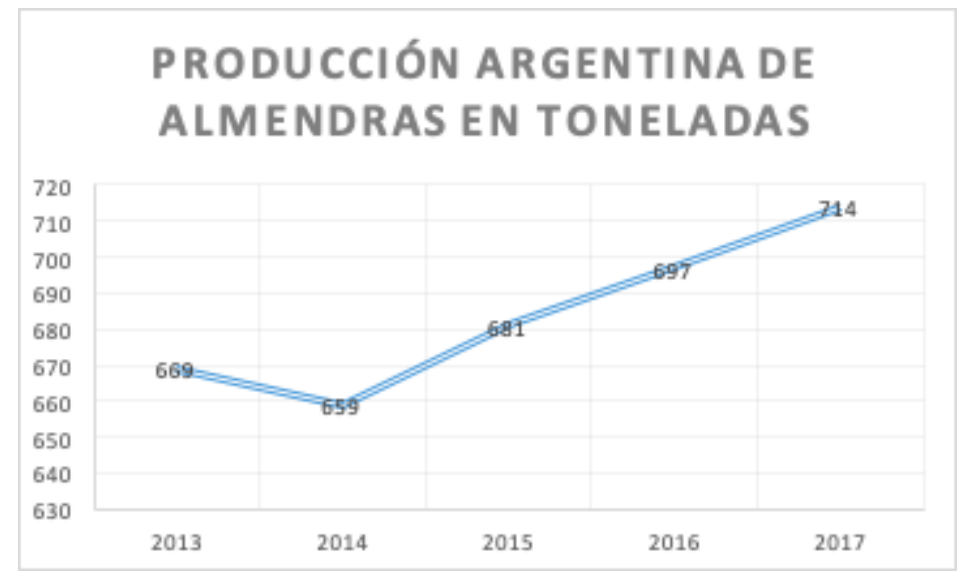

Esquema 5: Producción argentina de almendras en toneladas.

Fuente: Elaboración propia basada en datos de referencia ${ }^{21}$

La producción mundial de almendras es liderada por Estados Unidos, con un promedio del $79 \%$, seguido de Australia y España con el $5 \%$ y $7 \%$ respectivamente.

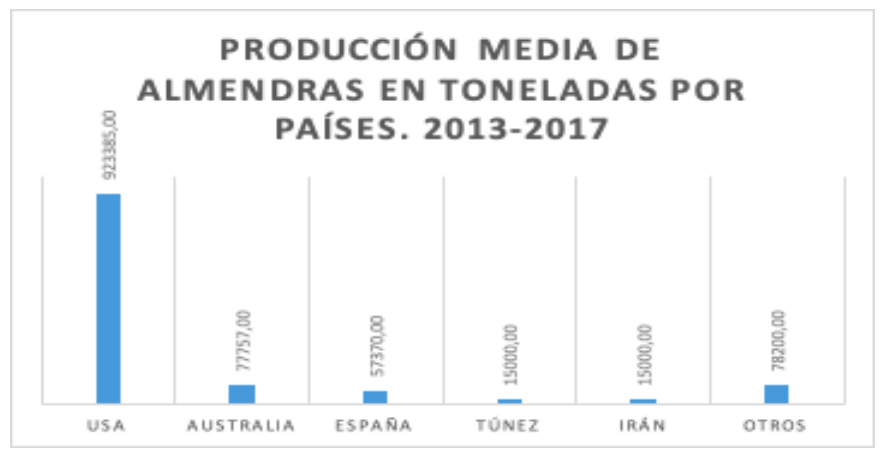

Esquema 6: Producción media de almendras en toneladas por países. 2013-2017.

Fuente: Elaboración propia basada en datos de referencia ${ }^{22}$

\footnotetext{
${ }^{20}$ FAO. Recuperado de: http://www.fao.org/faostat/es/\#data/QC Información tomada el 26 de octubre de 2019

21 FAO. Recuperado de: http://www.fao.org/faostat/es/\#data/QC Información tomada el 26 de octubre de 2019

22 International Nut \& Dried Fruit Council (INC). Recuperado de: https://www. nutfruit.org/industry/technicalresources?category=statistical-yearbooks Información tomada el 18 de noviembre de 2019
} 
La producción de almendras en Argentina se destina casi en su totalidad al mercado doméstico, ya que solo se exporta un pequeño porcentaje de la misma, que va del $4 \%$ al 10\%. En 2017 el consumo nacional de almendras alcanzó $126 \mathrm{gr} / \mathrm{hb} / \mathrm{año}^{23}$.

Las exportaciones de almendras alcanzaron su cantidad más alta en el año 2016, siendo los principales destinos España, Uruguay y Paraguay en lo que comprende del 2013 al 2017. El precio promedio FOB por tonelada es de USD 6.955

\begin{tabular}{|l|l|l|l|l|l|l|}
\hline \multicolumn{1}{|l|}{} & \multicolumn{1}{|c|}{2013} & \multicolumn{1}{|c|}{2014} & \multicolumn{1}{|l|}{2015} & \multicolumn{1}{|l|}{2016} & 2017 \\
\hline EXPORTACIONES DE ALMENDRAS & $257.715,00$ & $13.458,00$ & $501.690,00$ & $2.099 .014,00$ & $450.520,77$ \\
\hline Monto FOB en USD & 33,39 & 1,22 & 69,24 & 923,83 & 69,19 \\
\hline Volumen en toneladas & $7.718,33$ & $11.031,15$ & $7.245,67$ & $2.272,08$ & $6.511,36$ \\
\hline Precio promedio (USD FOB/ton) &
\end{tabular}

Las cifras comprenden exportaciones de almendras con cáscara y sin cáscara, correspondientes a las partidas arancelarias 0821100 y 08021200 , respectivamente.

Tabla 2: Exportaciones de almendras. 2013-2017.

Fuente: Elaboración propia basada en datos de referencia ${ }^{24}$

Para abastecer el mercado doméstico se importaron almendras en el período comprendido entre 2013 y 2017, los principales países importadores fueron Chile y Estados Unidos.

\begin{tabular}{|l|l|l|l|l|l|l|}
\hline \multicolumn{1}{|c|}{2013} & \multicolumn{1}{|c|}{2014} & 2015 & 2016 & 2017 \\
\hline \multicolumn{2}{|l|}{ IMPORTACIONES DE ALMENDRAS } & $15.387 .368,00$ & $19.561 .311,00$ & $15.262 .972,00$ & $16.437 .788,00$ & $21.937 .814,00$ \\
\hline Monto CIF en USD & $1.919,21$ & $1.998,17$ & $1.379,03$ & $2.348,22$ & $3.155,35$ \\
\hline Volumen en toneladas & $8.017,55$ & $9.789,61$ & $11.067,90$ & $7.000,11$ & $6.952,58$ \\
\hline Precio promedio (USD CIF/ton)
\end{tabular}

Las cifras comprenden importaciones de almendras con cáscara y sin cáscara, correspondientes a las partidas arancelarias 0821100 y 08021200 , respectivamente.

Tabla 3: Importaciones de almendras. 2013-2017.

Fuente: Elaboración propia basada en datos de referencia ${ }^{25}$

\footnotetext{
${ }^{23}$ Alimentos Argentinos. Recuperado de:

http://www.alimentosargentinos.gob.ar/HomeAlimentos/Cadenas $\% 20 \mathrm{de} \% 20 \mathrm{Valor} \% 20 \mathrm{de} \% 20$ Alimentos $\% 20$ y $\% 20 \mathrm{Bebidas} / \mathrm{in}$ formes/Resumen\%20Cadena 2019 ALMENDRA.pdf Información tomada el 18 de noviembre de 2019.

24 INDEC. Recuperado de: https://comex.indec.gov.ar/search/exports/2017/Y/8021100,8021200/Información tomada el 18 de noviembre de 2019.

25 INDEC. Recuperado de: https://comex.indec.gov.ar/search/exports/2017/Y/8021100,8021200/Información tomada el 18 de noviembre de 2019.
} 
2.4. Producción de Avellana en Argentina

La avellana es el fruto tipo nuez del avellano común, Corylus Avellana. Las principales variedades de avellanas que se cultivan en el territorio argentino son: Tonda Di Giffoni y Barcelona.

En el mercado internacional la avellana se comercializa (1) con cáscara; (2) pelada (entera, fileteada o molida); (3) blanqueada (entera, fileteada, molida y en harina); (4) como aceite de avellana y (5) como crema untable. Argentina comercializa avellanas con cáscara $(40 \%)$ y avellanas sin cáscara $(60 \%)^{26}$.

El avellano ${ }^{27}$ es un árbol muy cultivado en zonas mediterráneas de clima templado, frío y húmedo con influencia oceánica. No se adapta bien a condiciones ambientales secas. Las plantas en producción requieren una pluviometría superior a $800 \mathrm{~mm}$, regularmente distribuidos en primavera-verano.

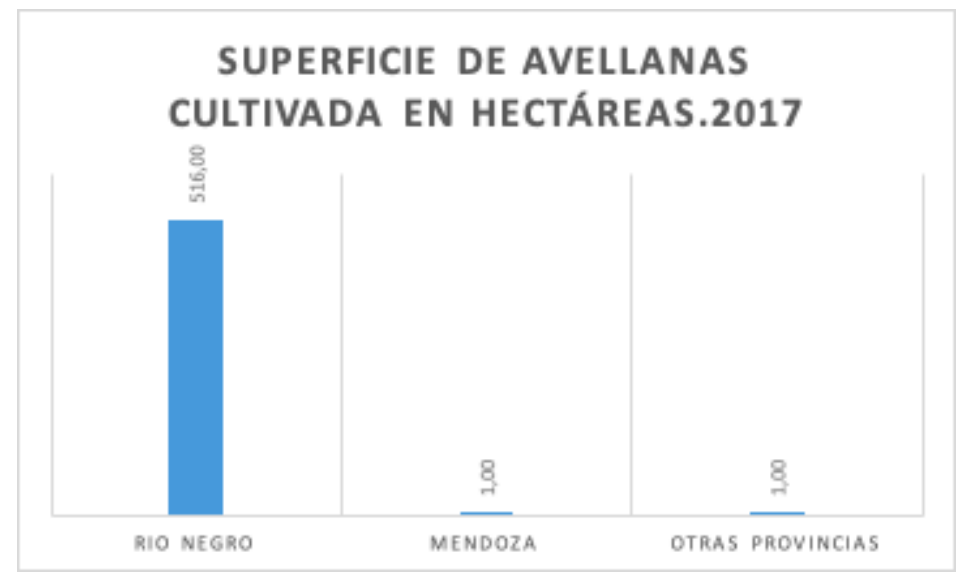

Esquema 7: Superficie de avellanas cultivada en hectáreas. 2017.

Fuente: Elaboración propia basada en datos de referencia ${ }^{28}$

La producción argentina de avellanas en el año 2017 fue de 269,7 toneladas ${ }^{29}$.

\footnotetext{
${ }^{26}$ Alimentos Argentinos. Recuperado de:

http://www.alimentosargentinos.gob.ar/HomeAlimentos/Publicaciones/Revista/AA 74.pdf Información tomada el 20 de noviembre de 2019.

27 INTA. Recuperado de: https://inta.gob.ar/sites/default/files/avellano-dario martin2015 copy.pdf Información tomada el 26 de octubre de 2019.

28 Relevamiento Nacional de Frutos Secos. Universidad de Cuyo:

https://app.powerbi.com/view?r=eyJrljoiNWRkYmFIZjgtNzU4ZS00ZGQZLWJkNzYtNjgyNDI3NWM3YTU3liwidCI6ImZmNjdk ZTc3LWRjN2YtNGRIZC1iNjA3LWM4MDhkNWI4Zjk2MilsImMiOjR9 Información tomada el 20 de octubre de 2019.

${ }^{29}$ Alimentos Argentinos. Recuperado de:

http://www.alimentosargentinos.gob.ar/HomeAlimentos/Publicaciones/Revista/AA 74.pdf Información tomada el 20 de noviembre de 2019.
} 


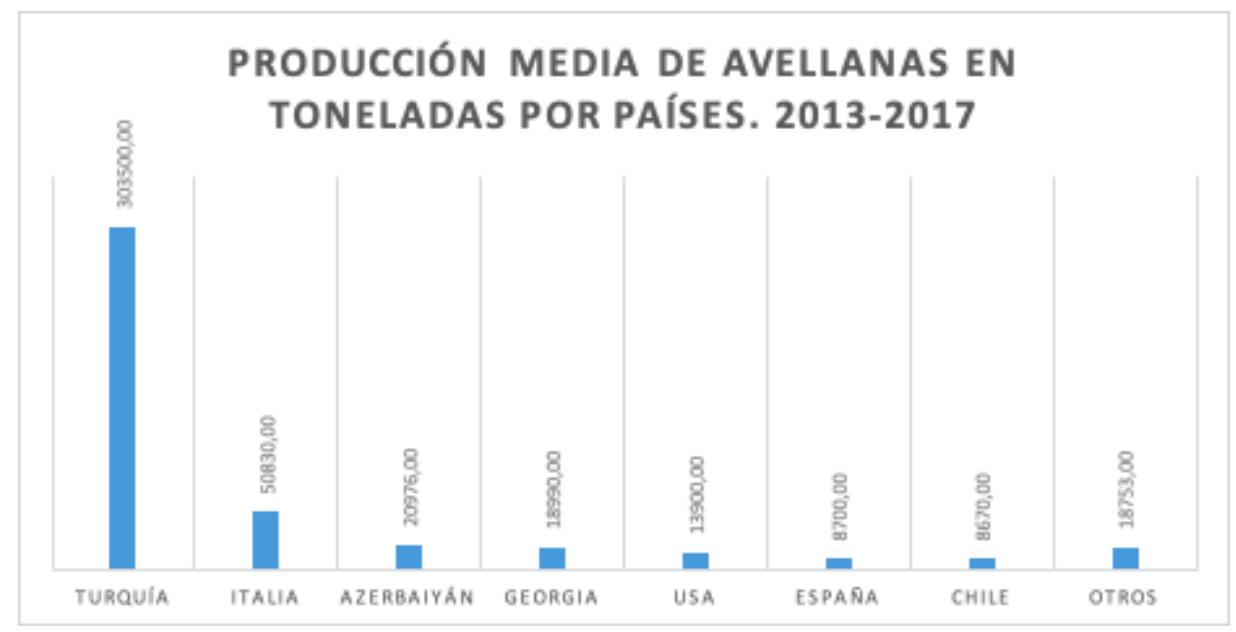

Esquema 8: Producción media de avellanas en toneladas por países. 2013-2017.

Fuente: Elaboración propia basada en datos de referencia ${ }^{30}$

A nivel mundial, la producción de avellanas es liderada por Turquía con el 68\%, seguido de Italia 11\%, Azerbaiyán 5\% y Georgia 4\%.

El consumo interno de avellanas en Argentina es de 250 toneladas anuales ${ }^{31}$, el destino principal es la industria de los chocolates, ya sea como pepita entera o partida para los chocolates en barra, o bien como crema untable tipo Nutella para la bombonería.

Prácticamente la totalidad de avellana con cáscara se consume en el mes de diciembre.

Los principales destinos de exportación de avellanas desde Argentina son Italia, Uruguay y Paraguay. El promedio de avellanas exportado anualmente es de 86,56 toneladas.

\footnotetext{
${ }^{30}$ International Nut \& Dried Fruit Council (INC). Recuperado de: https://www. nutfruit.org/industry/technicalresources?category=statistical-yearbooks Información tomada el 20 de noviembre de 2019

${ }^{31}$ Alimentos Argentinos. Avellanas. Recuperado de:

http://www.alimentosargentinos.gob.ar/HomeAlimentos/Frutas\%20secas/frutasecas/productos/Avellanas 2000/Avellanas.ht m Información tomada el 20 de noviembre de 2019.
} 


\begin{tabular}{|l|l|l|l|l|l|l|}
\hline \multicolumn{1}{|c|}{2013} & \multicolumn{1}{|c|}{2014} & 2015 & \multicolumn{1}{|c|}{2016} & 2017 \\
\hline \multicolumn{2}{|l|}{ EXPORTACIONES DE AVELLANAS } \\
\hline Monto FOB en USD & $211.065,00$ & $123.543,00$ & $7.825,00$ & $648.958,00$ & $831.054,00$ \\
\hline Volumen en toneladas & 57,64 & 31,32 & 0,55 & 113,36 & 229,96 \\
\hline Precio promedio (USD FOB/ton) & $3.661,72$ & $3.944,54$ & $14.227,27$ & $5.724,75$ & $3.613,91$ \\
\hline
\end{tabular}

Las cifras comprenden exportaciones de avellanas con cáscara y sin cáscara, correspondientes a las partidas arancelarias 08022100 y 08022200 respectivamente.

Tabla 4: Exportaciones de avellanas 2013-2017.

Fuente: Elaboración propia basada en datos de referencia ${ }^{32}$

Las importaciones de avellanas para abastecer el mercado doméstico argentino vienen de Chile, Turquía y España. El promedio de avellanas importado anualmente es de 221,73 toneladas.

\begin{tabular}{|l|l|l|l|l|l|l|}
\hline \multicolumn{2}{|l|}{} & 2013 & 2014 & 2015 & 2016 & 2017 \\
\hline \multicolumn{2}{|l|}{ IMPORTACIONES DE AVELLANAS } \\
\hline Monto CIF en USD & $1.331 .019,00$ & $1.502 .690,00$ & $2.345 .916,00$ & $1.577 .278,00$ & $2.480 .866,76$ \\
\hline Volumen en toneladas & 216,96 & 174,06 & 182,70 & 177,95 & 356,98 \\
\hline Precio promedio (USD CIF/ton) & $6.134,86$ & $8.633,17$ & $12.840,26$ & $8.863,60$ & $6.949,60$ \\
\hline
\end{tabular}

Las cifras comprenden importaciones de avellanas con cáscara y sin cáscara, correspondientes a las partidas arancelarias 08022100 y 08022200 respectivamente.

Tabla 5: Importaciones de avellanas 2013-2017.

Fuente: Elaboración propia basada en datos de referencia ${ }^{33}$

\subsection{Producción de Castaña en Argentina}

La castaña es el fruto que se obtiene del castaño común (Castanea Sativa). Se comercializa bajo diferentes presentaciones ${ }^{34}$ : (1) tostadas, (2) hervidas, (3) confitadas en

\footnotetext{
32 INDEC. Recuperado de: https://comex.indec.gov.ar/search/exports/2017/Y/8021100,8021200/Información tomada el 18 de noviembre de 2019

33 INDEC. Recuperado de: https://comex.indec.gov.ar/search/exports/2017/Y/8021100,8021200/ Información tomada el 18 de noviembre de 2019

34 INTA. Recuperado de: https://inta.gob.ar/sites/default/files/inta bouhier territorio.pdf Información tomada el 26 de octubre de 2019.
} 
puré, (4) molidas, (5) en almíbar, (6) cristalizadas y (7) glaseadas. En territorio argentino la comercialización de castaña se hace con cáscara.

El castaño ${ }^{35}$ es un árbol que vive desde el nivel del mar hasta que entra en contacto con las coníferas de alta montaña, su estado óptimo se encuentra entre los 500 y 1.200 metros de altitud. Presenta mejor tolerancia a los climas templados y con bastante humedad.

La totalidad de los cultivos de castaña en Argentina se encuentran en la provincia de Mendoza.

\section{SUPERFICIE DE CASTAÑA CULTIVADA}

EN HECTÁREAS. 2017

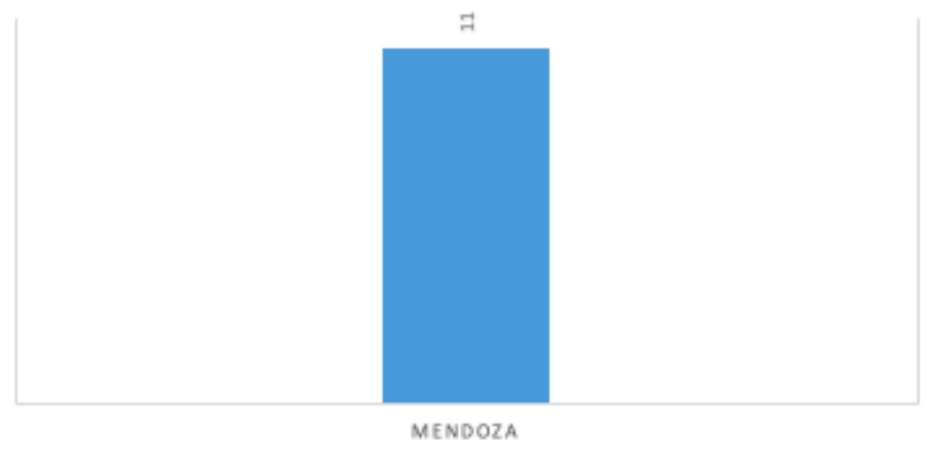

Esquema 9: Superficie de castaña cultivada en hectáreas. 2017.

Fuente: Elaboración propia basada en datos de referencia ${ }^{36}$

A nivel mundial, China concentra el $85 \%$ de la producción de castañas, seguido de Bolivia con el $3 \%$ y Turquía con el $3 \%$.

\footnotetext{
35 Infoagro. Recuperado de: https://www.infoagro.com/frutas/frutos secos/castano.htm Información tomada el 21 de noviembre de 2019.

${ }^{36}$ Relevamiento Nacional de Frutos Secos. Universidad de Cuyo:

https://app.powerbi.com/view?r=eyJrljoiNWRkYmFIZjgtNzU4ZS00ZGQZLWJkNzYtNjgyNDI3NWM3YTU3liwidCI6ImZmNjdk ZTc3LWRjN2YtNGRIZC1iNjA3LWM4MDhkNWI4Zjk2MilsImMiOjR9 Información tomada el 20 de octubre de 2019.
} 


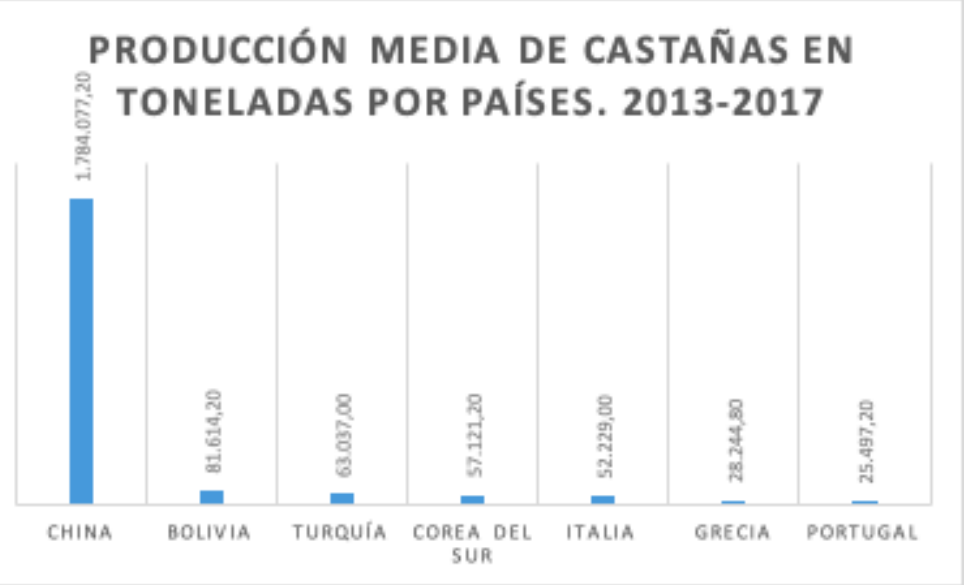

Esquema 10: Producción media de castañas en toneladas por países. 2013-2017.

Fuente: Elaboración propia basada en datos de referencia ${ }^{37}$

Según datos del INDEC ${ }^{38}$, no se reportan exportaciones de castañas de Argentina al mercado internacional. En cuanto a las importaciones, la última de la que se tiene registro corresponde al año 2013 desde Bolivia, por valor de 1,93 toneladas con un monto CIF en USD de 1.296.

2.6. Producción de Castaña de Cajú en Argentina

La castaña de cajú proviene del árbol Anacardium Occidentale, es también llamada como: nuez de la india, cajú, merei, anacardo, cajuil o marañón ${ }^{39}$. Entre las variedades más cultivadas se destacan Vengurla, Bhubaneshwar, Kanaka y Dhana Selection.

La castaña de cajú se comercializa: (1) tostada sin cáscara y (2) en aceite, para este análisis los datos corresponden a la tipo tostada.

El árbol del anacardo crece en forma silvestre en muchos países tropicales, no sujetos a heladas, lo que indica que este cultivo es rústico. Es un árbol bajo de 7-20 metros de altura, generalmente ramificado en su base.

\footnotetext{
${ }^{37}$ FAO. Recuperado de: http://www.fao.org/faostat/es/\#data/QC Información tomada el 21 de noviembre de 2019

38 INDEC. Recuperado de: https://comex.indec.gov.ar/search/imports/2019/Y/8024100,8024200/ Información tomada el 21 de noviembre de 2019

${ }^{39}$ Botanical Online. Recuperado de: https://www.botanical-online.com/botanica/anacardo-planta-caracteristicas Información tomada el 26 de noviembre de 2019.
} 
A nivel mundial, la producción de castañas de cajú la lideran Vietnam (39\%), India (26\%) y Costa de Marfil (22\%).

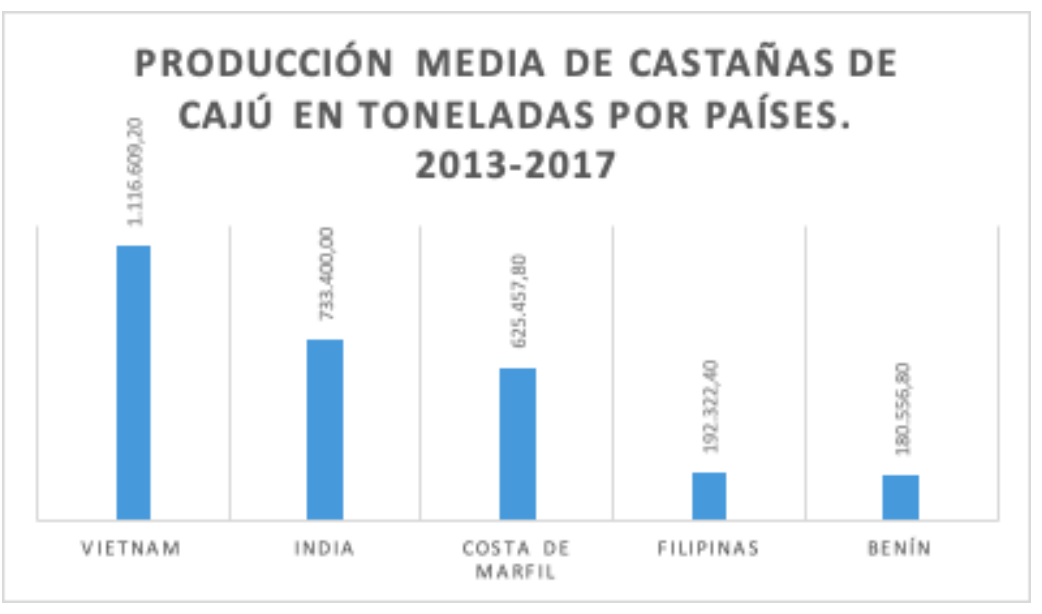

Esquema 11: Producción media de castañas de cajú en toneladas por países. 2013- 2017.

Fuente: Elaboración propia basada en datos de referencia ${ }^{40}$

El territorio argentino no produce ${ }^{41}$ castañas de cajú, por lo que se importan de Brasil para abastecer la demanda interna.

\begin{tabular}{|l|l|l|l|l|l|l|}
\hline \multicolumn{1}{|l|}{} & \multicolumn{1}{|c|}{2013} & \multicolumn{1}{|c|}{2014} & \multicolumn{1}{|c|}{2015} & \multicolumn{1}{l|}{2016} & 2017 \\
\hline \multicolumn{2}{|l|}{ IMPORTACIONES DE CASTANAS DE CAJÚ } \\
\hline Monto CIF en USD & $3.153 .699,00$ & $2.966 .338,00$ & $4.513 .537,00$ & $5.434 .508,00$ & $8.489 .623,93$ \\
\hline Volumen en toneladas & 701,56 & 601,34 & 606,33 & 715,19 & 934,57 \\
\hline Precio promedio (USD CIF/ton) & $4.495,27$ & $4.932,88$ & $7.444,03$ & $7.598,69$ & $9.083,99$ \\
\hline
\end{tabular}

Las cifras comprenden importaciones de nueces de cajú sin cáscara, correspondientes a la partida arancelaria 08013200.

Tabla 6: Importaciones de castañas de cajú. 2013-2017.

Fuente: Elaboración propia basada en datos de referencia ${ }^{42}$

\footnotetext{
${ }^{40}$ FAO. Recuperado de: http://www.fao.org/faostat/es/\#data/QC Información tomada el 21 de noviembre de 2019

41 INTA. Recuperado de: https://inta.gob.ar/sites/default/files/inta_bouhier_territorio.pdf Información tomada el 26 de octubre de 2019.

42 INDEC. Recuperado de: https://comex.indec.gov.ar/search/imports/2019/Y/8024100,8024200/Información tomada el 21 de noviembre de 2019
} 
2.7. Producción de Castaña o Nuez de Pará, nuez de Brasil o Bacurí en Argentina

La nuez de Brasil Bertholletia excelsa, proviene de un árbol nativo de Sudamérica, endémico de la Amazonía, específicamente de Bolivia, Brasil y Perú.

El fruto de la nuez de Brasil proviene de uno de los árboles más altos de la pluviselva tropical de la cuenca del Amazonas. Los frutos caen naturalmente al suelo y son recolectados, descascarados y comercializados.

El castañero de las nueces de Brasil $^{43}$ es un árbol muy alto, está entre los más altos de la selva amazónica, de entre 30 y 50 metros de altura. Cuando madura, libera las semillas que se encuentran en su interior (las nueces de Brasil). El árbol crece en forma natural en los bosques amazónicos de Brasil, Bolivia y Perú, en suelos aluviales profundos, ricos en materia orgánica, bien drenados y en terreno elevado.

A nivel internacional la producción de nueces de Brasil la lidera Bolivia, con un porcentaje del $77 \%$ seguido de Perú y Brasil, con el $16 \%$ y $7 \%$ respectivamente.

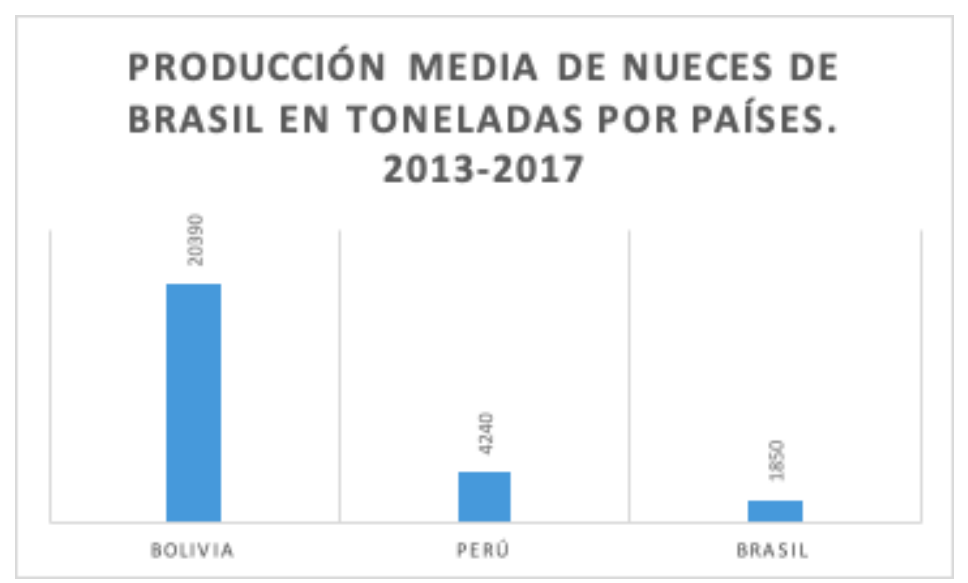

Esquema 12: Producción media de nueces de Brasil en toneladas por países. 2013-2017.

Fuente: Elaboración propia basada en datos de referencia ${ }^{44}$

\footnotetext{
${ }^{43}$ Botanical Online. Recuperado de: https://www.botanical-online.com/cultivo/nueces-brasil-como-plantar-cuidados Información tomada el 30 de noviembre de 2019

44 International Nut \& Dried Fruit Council (INC). Recuperado de: https://www.nutfruit.org/industry/technicalresources?category=statistical-yearbooks Información tomada el 26 de octubre de 2019
} 
Argentina no produce nueces de Brasil en su territorio, por lo que se importan de Bolivia para abastecer el mercado interno.

\begin{tabular}{|l|l|l|l|l|l|l|}
\hline \multicolumn{1}{|l|}{} & \multicolumn{1}{|c|}{2013} & \multicolumn{1}{|c|}{2014} & \multicolumn{1}{|c|}{2015} & \multicolumn{1}{l|}{2016} & 2017 \\
\hline \multicolumn{2}{|l|}{ IMPORTACIONES DE NUECES DE BRASIL } \\
\hline Monto CIF en USD & $461.322,00$ & $262.491,00$ & $315.228,00$ & $405.903,00$ & $105.019,50$ \\
\hline Volumen en toneladas & 61,93 & 33,80 & 41,97 & 52,40 & 12,97 \\
\hline Precio promedio (USD CIF/ton) & $7.448,85$ & $7.766,01$ & $7.511,69$ & $7.746,68$ & $8.097,11$ \\
\hline
\end{tabular}

Las cifras comprenden importaciones de nueces de Brasil con cáscara y sin cáscara, correspondientes a la partidas arancelarias 08012100 y 08012200 , respectivamente.

Tabla 7: Importaciones de nueces de Brasil. 2013-2017.

Fuente: Elaboración propia basada en datos de referencia ${ }^{45}$

\subsection{Producción de Nuez Nogal en Argentina}

La nuez nogal o nuez común proviene del árbol Juglans regia, las principales variedades que produce el territorio argentino son Chandler y criollo.

La nuez nogal se comercializa (1) con cáscara y (2) sin cáscara. Tradicionalmente las ventas a mercados externos se componen de un $51 \%$ de nuez con cáscara y un $49 \%$ de nuez sin cáscara, en relación al valor total exportado.

El cultivo de nogal ${ }^{46}$ se adapta a todo tipo de terreno, aunque se desarrolla en plenitud en suelos profundos y bien drenados. Puede resistir hasta $-20{ }^{\circ} \mathrm{C}$, pero la producción puede verse resentida si se registran heladas durante el período de floración.

La nuez nogal es el fruto seco con mayor superficie cultivada en Argentina, concentrando el $61 \%$ del total de frutos secos cultivados.

\footnotetext{
45 INDEC. Recuperado de: https://comex.indec.gov.ar/search/imports/2019/Y/8024100,8024200/ Información tomada el 30 de noviembre de 2019

${ }^{46}$ Alimentos Argentinos. Recuperado de:

http://www.alimentosargentinos.gob.ar/contenido/revista/ediciones/37/cadenas/Frutas secas nuez.htm Información tomada el 26 de octubre de 2019.
} 


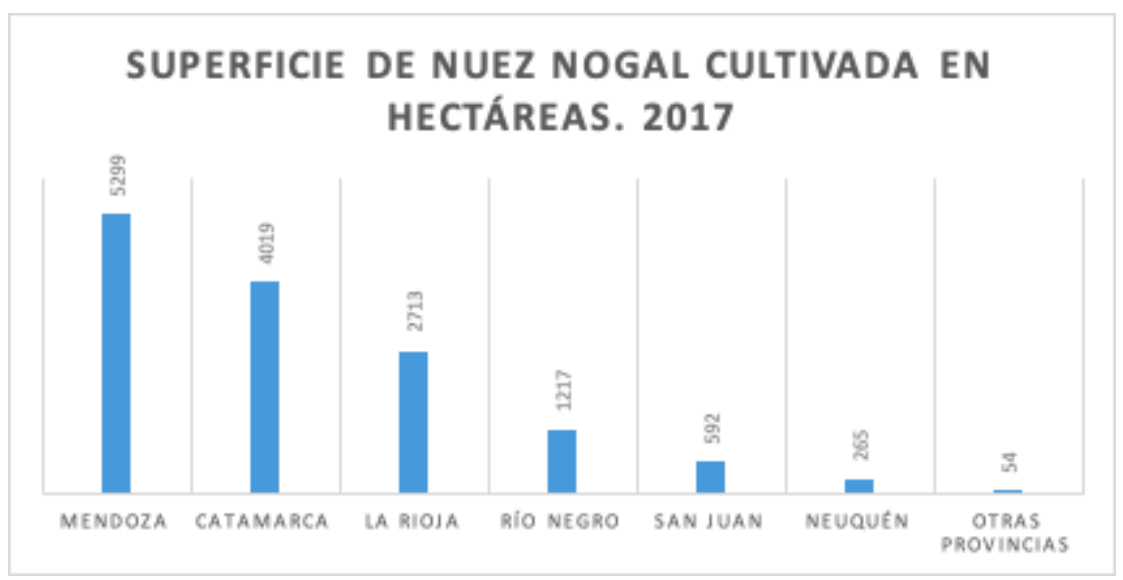

Esquema 13: Superficie de nuez nogal cultivada en hectáreas. 2017.

Fuente: Elaboración propia basada en datos de referencia ${ }^{47}$

Argentina ocupa el puesto número 22 a nivel mundial en producción de nuez nogal, según datos de la $\mathrm{FAO}^{48}$ actualizados al 2017, con una producción estimada en 12.050 toneladas anuales, presentando un crecimiento del 3\% en la producción de 2014 a 2017.

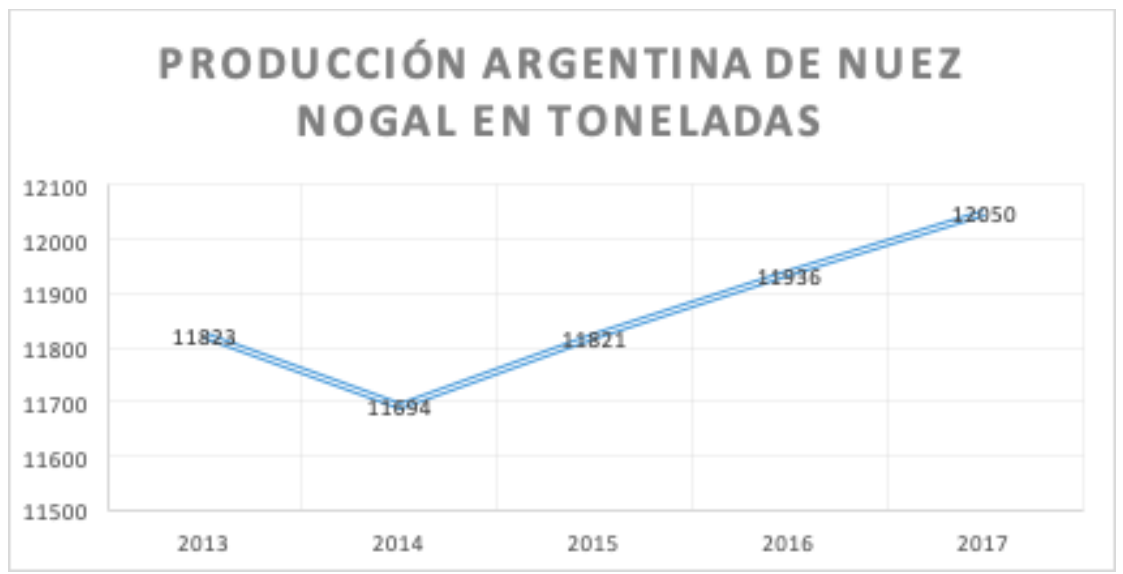

Esquema 14: Producción argentina de nuez nogal en toneladas. 2013- 2017.

Fuente: Elaboración propia basada en datos de referencia ${ }^{49}$

China lidera la producción mundial de nuez de nogal con el $40 \%$ del total producido, seguido de USA $32 \%$ y Chile $3 \%$.

\footnotetext{
47 Relevamiento Nacional de Frutos Secos. Universidad de Cuyo: https://app.powerbi.com/view?r=eyJrljoiNWRkYmFIZjgtNzU4ZS00ZGQzLWJkNzYtNjgyNDI3NWM3YTU3liwidCI6ImZmNjdk ZTc3LWRjN2YtNGRIZC1iNjA3LWM4MDhkNWI4Zjk2MilsImMiOjR9 Información tomada el 26 de octubre de 2019.

${ }^{48}$ FAO. Recuperado de: http://www.fao.org/faostat/es/\#data/QC Información tomada el 26 de octubre de 2019

49 FAO. Recuperado de: http://www.fao.org/faostat/es/\#data/QC Información tomada el 26 de octubre de 2019
} 


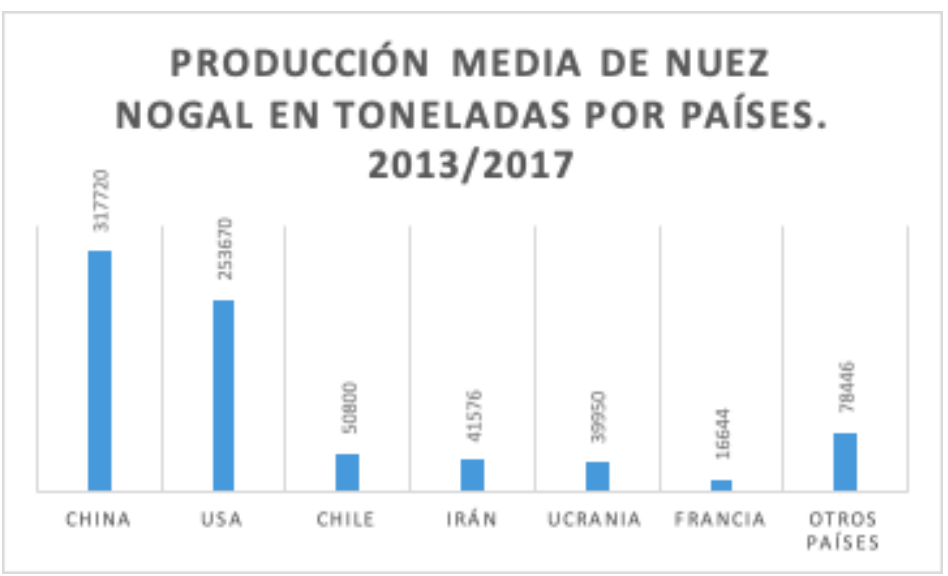

Esquema 15: Producción media de nuez nogal en toneladas por países. 2013-2017.

Fuente: Elaboración propia basada en datos de referencia ${ }^{50}$

La nuez nogal es el fruto seco de mayor consumo en Argentina ${ }^{51}$, alcanzando los 300 gramos per cápita. El 80\% de la producción total de nuez nogal en Argentina se destina al consumo interno.

Los países donde se exporta nuez nogal argentina son: Brasil, Uruguay, Paraguay, Italia, Turquía, España, Marruecos, Francia y Rusia con un precio promedio FOB por tonelada de USD 4.174,31.

\begin{tabular}{|l|l|l|l|l|l|l|}
\hline \multicolumn{1}{|c|}{2013} & 2014 & 2015 & 2016 & 2017 \\
\hline EXPORTACIONES DE NUEZ NOGAL \\
\hline Monto FOB en USD & $9.699 .496,00$ & $15.156 .605,00$ & $10.904 .903,00$ & $5.837 .466,00$ & $13.185 .391,00$ \\
\hline Volumen en toneladas & $2.113,82$ & $3.245,14$ & $3.036,10$ & $1.474,69$ & $3.245,89$ \\
\hline Precio promedio (USD FOB/ton) & $4.588,61$ & $4.670,56$ & $3.591,75$ & $3.958,44$ & $4.062,18$ \\
\hline
\end{tabular}

Las cifras comprenden exportaciones de nueces de nogal con cáscara y sin cáscara, correspondientes a la partidas arancelarias 08023100 y 08023200 , respectivamente.

Tabla 8: Exportaciones de nuez nogal. 2013-2017.

Fuente: Elaboración propia basada en datos de referencia ${ }^{52}$

\footnotetext{
50 International Nut \& Dried Fruit Council (INC). Recuperado de: https://www.nutfruit.org/industry/technicalresources?category=statistical-yearbooks Información tomada el 30 de noviembre de 2019

${ }^{51}$ Cadena de Nuez Nogal, Alimentos Argentinos. Recuperado de:

http://www.alimentosargentinos.gob.ar/HomeAlimentos/Cadenas\%20de\%20Valor\%20de\%20Alimentos\%20y\%20Bebidas/in formes/Resumen_Cadena_2019 NUEZ_NOGAL_sept_FINAL.pdf Información tomada el 30 de noviembre de 2019

52 INDEC. Recuperado de: https://comex.indec.gov.ar/search/imports/2019/Y/8024100,8024200/Información tomada el 30 de noviembre de 2019
} 
Las importaciones de nuez nogal al territorio argentino provienen principalmente de Chile, en el 2016 se importó además nueces de la India y en el 2017 de Brasil.

\begin{tabular}{|l|l|l|l|l|l|l|}
\hline \multicolumn{1}{|l|}{2013} & \multicolumn{1}{|c|}{2014} & \multicolumn{1}{|c|}{2015} & \multicolumn{1}{|c|}{2016} & 2017 \\
\hline \multicolumn{2}{|l|}{ IMPORTACIONES DE NUEZ NOGAL } \\
\hline Monto CIF en USD & $1.044 .731,00$ & $312.456,00$ & $495.609,00$ & $1.585 .752,00$ & $408.563,00$ \\
\hline Volumen en toneladas & 90,74 & 29,00 & 58,60 & 245,96 & 77,48 \\
\hline $\begin{array}{l}\text { Precio promedio (USD } \\
\text { CIF/ton) }\end{array}$ & $11.513,08$ & $10.774,34$ & $8.457,49$ & $6.447,19$ & $5.273,14$ \\
\hline
\end{tabular}

Las cifras comprenden importaciones de nueces de nogal con cáscara y sin cáscara, correspondientes a la partidas arancelarias 08023100 y 08023200 , respectivamente.

Tabla 9: Exportaciones de nuez nogal. 2013-2017.

Fuente: Elaboración propia basada en datos de referencia ${ }^{53}$

\subsection{Producción de Nuez Pecán en Argentina}

La nuez pecán proviene de un árbol frutal nativo de Estados Unidos Carya illinoinensis, las principales variedades en el territorio argentino son: Stuart, Desirable, Mahan y Pawne.

La nuez pecán se comercializa (1) con cáscara o (2) pelada. De la cosecha 2017, el porcentaje de nuez pecán con cáscara comercializada correspondió al $44 \%$ y de nuez nogal sin cáscara el $56 \%$.

El pecán ${ }^{54}$ requiere un período de crecimiento entre 170 y 280 días que se extiende desde la última helada invernal hasta la primera helada otoñal. El fruto permanece en la planta por un período de 6 hasta 7 meses. El árbol del pecán crece mejor cuando la temperatura media del período de crecimiento es alta, alrededor de $23^{\circ} \mathrm{C}$.

\footnotetext{
53 INDEC. Recuperado de: https://comex.indec.gov.ar/search/imports/2019/Y/8024100,8024200/Información tomada el 30 de noviembre de 2019

54 INTA. Recuperado de: https://inta.gob.ar/sites/default/files/ficha de pecan may 21 mayo 2018.pdf Información tomada el 1 de diciembre de 2019
} 
Argentina tiene un total de 4.781 hectáreas cultivadas de nuez pecán en su territorio, distribuidas de la siguiente manera:

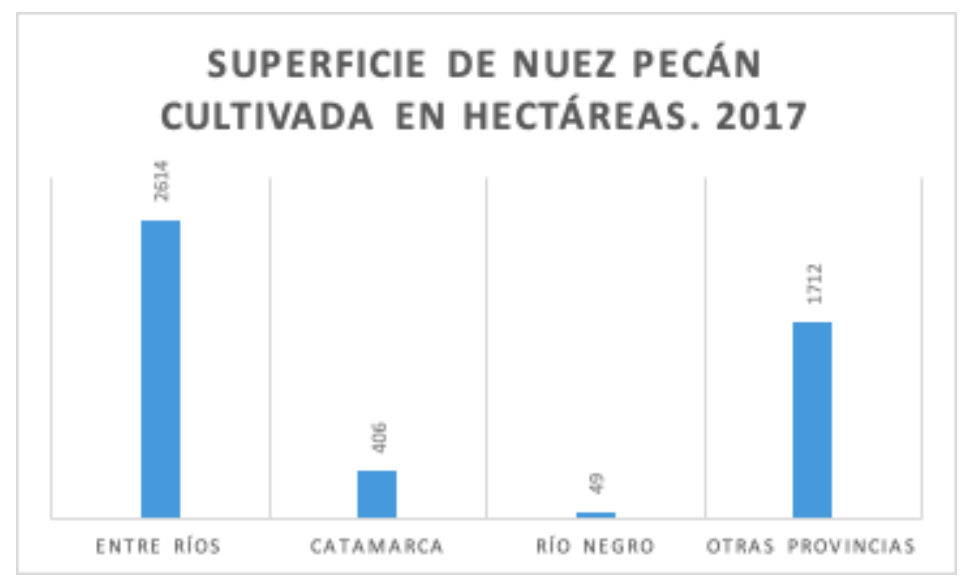

Esquema 16: Superficie de nuez pecán cultivada en hectáreas. 2017.

Fuente: Elaboración propia basada en datos de referencia ${ }^{55}$

En Argentina actualmente se producen $1.100^{56}$ toneladas de nuez pecán, cabe aclarar que hay una gran cantidad de hectáreas implantadas que aún no se encuentran en producción.

A nivel Mundial, México lidera la producción de nuez pecán con el 52\% del total producido, seguido de USA y Sudáfrica con el $41 \%$ y $5 \%$ respectivamente.

55 Relevamiento Nacional de Frutos Secos. Universidad de Cuyo: https://app. powerbi.com/view?r=eyJrljoiNWRkYmFIZjgtNzU4ZS00ZGQZLWJkNzYtNjgyNDI3NWM3YTU3liwidCI6ImZmNidk ZTc3LWRjN2YtNGRIZC1iNjA3LWM4MDhkNWI4Zjk2MilsImMiOjR9 Información tomada el 27 de octubre de 2019.

${ }^{56}$ Alimentos Argentinos. Cadena de la Nuez Pecán:

http://www.alimentosargentinos.gob.ar/HomeAlimentos/Cadenas\%20de\%20Valor\%20de\%20Alimentos\%20y\%20Bebidas/in formes/Resumen Cadena NUEZ PECAN mayo 2019.pdf Información tomada el 1 de diciembre de 2019. 


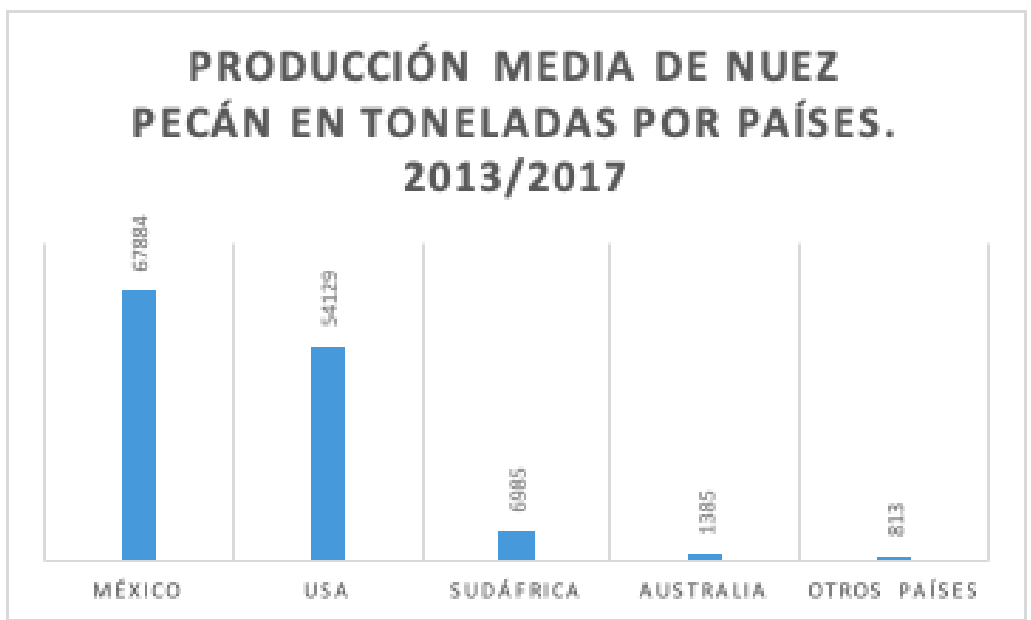

Esquema 17: Producción media de nuez pecán en toneladas por países. 2013-2017.

Fuente: Elaboración propia basada en datos de referencia ${ }^{57}$

Se estima que el consumo de nuez pecán ${ }^{58}$ en Argentina es de $10 \mathrm{gr} / \mathrm{hb} / \mathrm{año}$ y el $70 \%$ de la producción se destina al consumo interno, solo el 30\% se exporta a Vietnam, Argelia, Hong Kong y Uruguay.

\begin{tabular}{|l|l|l|l|l|l|l|}
\hline \multicolumn{1}{|l|}{} & \multicolumn{1}{|c|}{2013} & \multicolumn{1}{|c|}{2014} & \multicolumn{1}{|l|}{2015} & \multicolumn{1}{|l|}{2016} & 2017 \\
\hline EXPORTACIONES DE NUEZ PECÁN \\
\hline Monto FOB en USD & $120.608,00$ & $351.370,00$ & $316.805,00$ & $615.157,00$ & $1.411 .263,00$ \\
\hline Volumen en toneladas & 30,00 & 99,75 & 81,50 & 112,50 & 247,12 \\
\hline Precio promedio (USD FOB/ton) & $4.020,27$ & $3.522,51$ & $3.887,18$ & $5.468,06$ & $5.710,84$ \\
\hline
\end{tabular}

Las cifras comprenden exportaciones de Otros frutos de cáscara, correspondientes a la partida arancelaria 08029000.

Tabla 10: Exportaciones de nuez pecán 2013-2017.

Fuente: Elaboración propia basada en datos de referencia ${ }^{59}$

Para abastecer la demanda doméstica se importa nuez pecán de China.

\footnotetext{
57 International Nut \& Dried Fruit Council (INC). Recuperado de: https://www.nutfruit.org/industry/technicalresources?category=statistical-yearbooks Información tomada el 30 de noviembre de 2019

${ }^{58}$ Alimentos Argentinos Cadena de la Nuez Pecán:

http://www.alimentosargentinos.gob.ar/HomeAlimentos/Cadenas $\% 20$ de $\% 20$ Valor $\% 20$ de $\% 20$ Alimentos $\% 20$ y $\% 20$ Bebidas/in formes/Resumen_Cadena_NUEZ_PECAN_mayo_2019.pdf Información tomada el 1 de diciembre de 2019.

59 INDEC. Recuperado de: https://comex.indec.gov.ar/search/imports/2019/Y/8024100,8024200/Información tomada el 30 de noviembre de 2019
} 


\begin{tabular}{|l|l|l|l|l|l|l|}
\hline \multicolumn{1}{|l|}{2013} & \multicolumn{1}{|c|}{2014} & \multicolumn{1}{|c|}{2015} & \multicolumn{1}{|c|}{2016} & 2017 \\
\hline \multicolumn{2}{|l|}{ IMPORTACIONES DE NUEZ PECÁN } \\
\hline Monto CIF en USD & $21.079,00$ & $29.225,00$ & $20.808,00$ & $29.083,00$ & $16.613,00$ \\
\hline Volumen en toneladas & 1,00 & 1,00 & 1,00 & 1,50 & 3,49 \\
\hline Precio promedio (USD CIF/ton) & $21.079,00$ & $29.225,00$ & $20.808,00$ & $19.388,67$ & $4.760,17$ \\
\hline
\end{tabular}

Las cifras comprenden importaciones de Otros frutos de cáscara, correspondientes a la partida arancelaria 08029000.

Tabla 11: Importaciones de nuez pecán. 2013-2017.

Fuente: Elaboración propia basada en datos de referencia ${ }^{60}$

2.10. Producción de Pistacho en Argentina

La nuez de pistacho proviene del árbol pistachero (Pistacia Vera L.), en Argentina la principal variedad cultivada es Kerman.

El pistacho se comercializa (1) sin cáscara y (2) con cáscara. De la cosecha 2017, el porcentaje de pistacho con cáscara comercializado correspondió al $56 \%$ y de pistacho sin cáscara el $44 \%$.

El pistachero ${ }^{61}$ es una especie adaptada a climas templados y secos y pueden considerarse los $45^{\circ}$ como el límite septentrional de su cultivo en Europa y Asia. Es una planta resistente a la sequía (superior a otras especies frutales) y a las altas temperaturas del verano, pero no tolera un exceso de humedad.

En Argentina hay un total de 1.008 hectáreas cultivadas de pistachos. A continuación la distribución por provincia:

\footnotetext{
60 INDEC. Recuperado de: https://comex.indec.gov.ar/search/imports/2019/Y/8024100,8024200/ Información tomada el 30 de noviembre de 2019

61 Infoagro. Recuperado de: https://www.infoagro.com/frutas/frutos secos/pistacho.htm Información tomada el 1 de diciembre de 2019
} 
SUPERFICIE DE PISTACHO CULTIVADA EN

HECTÁREAS. 2017

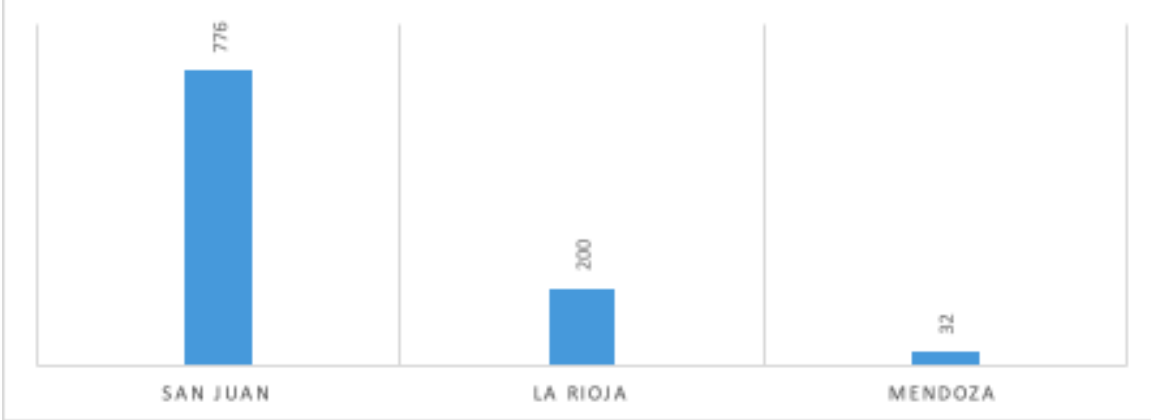

Esquema 18: Superficie de pistacho cultivada en hectáreas. 2017.

Fuente: Elaboración propia basada en datos de referencia ${ }^{2}$

Se estima una producción anual de pistachos en Argentina $^{63}$ de 613 toneladas.

A nivel mundial, la producción de pistachos es liderada por Estados Unidos, Irán y Turquía.

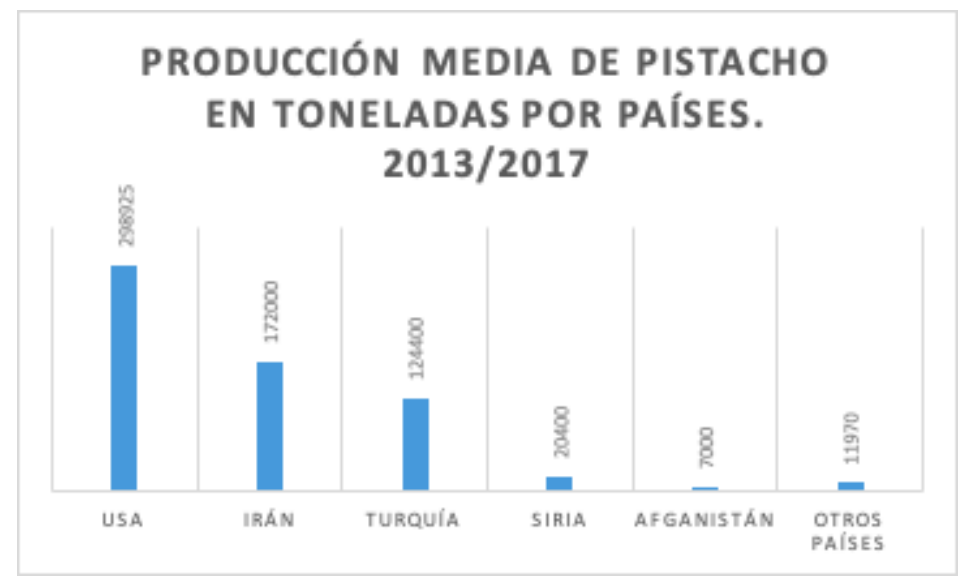

Esquema 19: Producción media de pistacho en toneladas por países. 2013-2017.

Fuente: Elaboración propia basada en datos de referencia ${ }^{64}$

\footnotetext{
62 Relevamiento Nacional de Frutos Secos. Universidad de Cuyo:

https://app.powerbi.com/view?r=eyJrljoiNWRkYmFIZjgtNzU4ZS00ZGQzLWJkNzYtNjgyNDI3NWM3YTU3liwidCI6ImZmNjdk ZTC3LWRjN2YtNGRIZC1iNjA3LWM4MDhkNWI4Zjk2MilsImMiOjR9 Información tomada el 1 de diciembre de 2019.

${ }^{63}$ Alimentos Argentinos. Recuperado de:

http://www.alimentosargentinos.gob.ar/HomeAlimentos/Publicaciones/Revista/AA 74.pdf Información tomada el 1 de diciembre de 2019.

64 International Nut \& Dried Fruit Council (INC). Recuperado de: https://www.nutfruit.org/industry/technicalresources?category=statistical-yearbooks Información tomada el 26 de octubre de 2019
} 
Las exportaciones de pistacho en Argentina durante 2013 a 2017 tuvieron como destinos:

Venezuela, Colombia, Uruguay, Brasil, España, Italia y Rusia.

\begin{tabular}{|l|l|l|l|l|l|l|}
\hline \multicolumn{1}{|l|}{2013} & 2014 & 2015 & 2016 & 2017 \\
\hline \multicolumn{2}{|l|}{ EXPORTACIONES DE PISTACHO } & \multicolumn{1}{|c|}{20} \\
\hline Monto FOB en USD & $1.561 .267,00$ & $1.015 .254,00$ & $1.892 .339,00$ & $815.403,00$ & $3.264 .394,00$ \\
\hline Volumen en toneladas & 139,76 & 108,91 & 152,00 & 52,46 & 397,00 \\
\hline $\begin{array}{l}\text { Precio promedio (USD } \\
\text { FOB/ton) }\end{array}$ & $11.171,06$ & $9.321,95$ & $12.449,60$ & $15.543,33$ & $8.222,65$ \\
\hline
\end{tabular}

Las cifras comprenden exportaciones de pistachos con cáscara y sin cáscara, correspondientes a las partidas arancelarias 08025100 y 08025200 , respectivamente.

Tabla 12: Exportaciones de pistacho. 2013-2017.

Fuente: Elaboración propia basada en datos de referencia65

Para abastecer el mercado interno argentino, se importan pistachos de Estados Unidos e Irán.

\begin{tabular}{|l|l|l|}
\hline & \multicolumn{1}{|c|}{2016} & \multicolumn{1}{|c|}{2017} \\
\hline IMPORTACIONES DE PISTACHO & & \\
\hline Monto CIF en USD & $156.545,00$ & $17.276,00$ \\
\hline Volumen en toneladas & 19,95 & 1,50 \\
\hline Precio promedio (USD CIF/ton) & $7.846,87$ & $11.517,33$ \\
\hline
\end{tabular}

Las cifras comprenden importaciones de pistachos con cáscara y sin cáscara, correspondientes a la partidas arancelarias 08025100 y 08025200 , respectivamente.

EI INDEC no reporta importaciones de pistacho en 2013, 2014 y 2015.

Tabla 13: Importaciones de pistacho 2016-2017.

Fuente: Elaboración propia basada en datos de referencia ${ }^{66}$

\footnotetext{
65 INDEC. Recuperado de: https://comex.indec.gov.ar/search/imports/2019/Y/8024100,8024200/ Información tomada el 30 de noviembre de 2019

66 INDEC. Recuperado de: https://comex.indec.gov.ar/search/imports/2019/Y/8024100,8024200/Información tomada el 30 de noviembre de 2019
} 
2.11. Potencial exportador de frutos secos argentinos al mercado internacional

El estudio de la producción argentina de frutos secos es útil para esbozar un panorama del sector a la fecha y evaluar su potencial de exportación.

Conforme a los datos y la información obtenida sobre la producción de frutos secos en Argentina durante los años 2013 al 2018/2019, llegamos a las siguientes conclusiones:

- La producción actual en el territorio, aún se encuentra por debajo de los grandes competidores mundiales, con un potencial desarrollo a corto plazo.

- La nuez nogal, nuez pecán y almendra concentran el $94 \%$ de la superficie cultivada de frutos secos a nivel nacional.

- Argentina no produce castañas de cajú y nueces de Brasil.

- Mendoza es la provincia con mayor cantidad de cultivos de frutos secos en Argentina.

- El cultivo con menor superficie cultivada en el territorio nacional es la castaña.

- Argentina exporta al mercado internacional: almendras, avellanas, nueces de nogal, nueces pecán y pistachos.

- Las dos especies de frutos secos que han presentado incremento en sus cultivos son: la almendra ( $8 \%$ ) y la nuez nogal $(3 \%)$

- Las exportaciones de avellanas se duplicaron durante 2016 y 2017 , pasando de 113,36 toneladas a 229,96 .

- Las exportaciones de nuez nogal tienen un promedio de 2.623,13 toneladas anuales y las importaciones para abastecer la demanda interna mantienen un promedio de 100 toneladas anuales.

- Las exportaciones de nuez pecán son relativamente altas en comparación al volumen importado. Con una media de 114 toneladas comercializadas al mercado internacional y 1,60 toneladas importadas al mercado doméstico.

- Las exportaciones de pistachos registran una media de 170 toneladas anuales, pasando de 52 toneladas en 2016 a 397 toneladas exportadas en 2017, esto gracias al incremento de la producción.

- Hasta 2015 Argentina abastecía el mercado interno de pistachos sin registrar importaciones, a partir de 2016 se comenzó a importar por valores mínimos 19,95 toneladas y 1,5 tonelada en 2017. 
Gracias a las anteriores afirmaciones podemos concluir que las especies de frutos secos con volúmenes de importaciones menores a las exportaciones corresponden a la nuez nogal, nuez pecán y pistacho, siendo las elegidas para exportar al mercado internacional. 


\section{ASPECTOS RELEVANTES PARA LA EXPORTACIÓN DE FRUTOS SECOS AL MERCADO INTERNACIONAL}

En el desarrollo de este capítulo se expondrá la visión operativa de aduanas, bancos, transportes y seguros internacionales necesarios para lograr el flujo de los frutos secos, desde Argentina como país exportador a Colombia como país importador.

En base al estudio de la producción argentina de frutos secos, expuesta en el capítulo dos de este proyecto, se evidenció que las tres especies con mayor potencial exportador son: nueces de nogal, nueces de pecán y pistachos, esto debido a que presentan volúmenes de importaciones menores a las exportaciones, lo que permite afirmar que hay producción suficiente para abastecer el mercado interno argentino y exportar.

La nuez nogal es el fruto seco con mayor superficie cultivada en Argentina, siendo la provincia de Mendoza quien lidera la producción con un 38\% del total cultivado. La provincia de San Juan también posee producción de nuez nogal con un 4\%, dada la coincidencia en procedencia geográfica con la producción argentina de pistacho, y para optimizar costos de flete interno, es la elegida para hacer la compra de la mercadería. En consecuencia a lo anterior, el lugar de origen para la exportación en Argentina es la provincia de San Juan y el puerto de destino en Colombia, el de la ciudad de Cartagena.

La nuez pecán concentra la mayor parte de su producción en la provincia de Entre Ríos, con el $55 \%$ del total cultivado. El lugar de origen para la exportación en Argentina es la provincia de Entre Ríos y el puerto de destino en Colombia, el de la ciudad de Cartagena.

El pistacho se produce principalmente en la provincia de San Juan con el $77 \%$ del total cultivado. El lugar de origen para la exportación en Argentina es la provincia de San Juan y el puerto de destino en Colombia, el de la ciudad de Cartagena. 


\subsection{Régimen aduanero}

Las bases sobre las que se asienta la operatoria aduanera del comercio exterior otorgan la capacidad de aplicar en situaciones concretas los conocimientos relacionados con las reglamentaciones y los tributos aduaneros, tales como la clasificación arancelaria de las mercaderías, su valoración ante aduana, aspectos del procedimiento de verificación y control, tributación local a la exportación y a la importación, y a los movimientos de capitales, los convenios para evitar la doble imposición; la devolución de tributos y otros diversos regímenes especiales destinados a favorecer la exportación ${ }^{67}$.

En Argentina, la Dirección General de Aduanas (DGA), es un órgano que integra la Administración Federal de Ingresos Públicos (AFIP) y tiene a su cargo la aplicación de la legislación relativa a la exportación de mercaderías, como así también el control del tráfico de los bienes que egresan en el territorio aduanero.

En Colombia, la Dirección de Impuestos y Aduanas Nacionales (DIAN) es la única autoridad competente para verificar la legalidad de los trámites aduaneros de importación y el cumplimiento de las obligaciones por parte de los usuarios aduaneros (personas naturales o jurídicas que intervienen directa o indirectamente en operaciones de importación).

En Argentina para oficiar como exportador, es necesario registrarse ante la AFIP como "operador de comercio exterior" conforme a la Resolución General No. 2570/200968, anexando la documentación correspondiente. Con el alta de este registro se habilita automáticamente la cuenta del exportador en el Banco de la Nación de la República Argentina.

En Colombia, para importar mercadería, es requisito estar registrado en el Registro Único Tributario- RUT con la responsabilidad de usuario aduanero y tener creada y habilitada la cuenta a través de los servicios informáticos electrónicos y el sistema informático aduanero SYGA- Importaciones ${ }^{69}$.

\footnotetext{
${ }^{67}$ Berman, J. (2014). Gestión del Comercio Exterior. (prefacio, pp.24)Buenos Aires: Edicon.

68 AFIP. Resolución General No. 2570/2009. Recuperado de: http://biblioteca.afip.gob.ar/dcp/REAG01002570_2009_02_27 Información tomada el 27 de enero de 2020.

69 GOV.CO. Portal Único del Estado Colombiano. Recuperado de: https://www.gov.co/servicios-y-tramites/t328 Información tomada el 27 de enero de 2020 .
} 
3.1.1. Información arancelaria

La clasificación arancelaria es una técnica y un requisito de las declaraciones aduaneras, que se aplica tanto en materia de importación como de exportación ${ }^{70}$.

Las tres especies de frutos secos elegidas para exportar de Argentina a Colombia son: nueces de nogal, nueces de pecán y pistachos. Cada una presenta sus particularidades en cuanto a condiciones de cultivo y características físicas.

A continuación se expondrá una tabla comparativa con la información aduanera para cada especie en Argentina y en Colombia:

70 Berman, J. (2014). Gestión del Comercio Exterior. (c.c. 5, pp.223) Buenos Aires: Edicon 


\begin{tabular}{|c|c|c|}
\hline NUECES DE NOGAL SIN CÁSCARA & Argentina & Colombia \\
\hline Posición arancelaria & 0802.32 .00 .00 & 0802.32 .00 .00 \\
\hline Derechos & $12 \%$ & $0 \%$ \\
\hline Reembolso & - & - \\
\hline Reintegro & $1,75 \%$ & - \\
\hline Impuesto al valor agregado (IVA) & - & $19 \%$ \\
\hline Barreras para arancelarias a considerar & no se detectaron & no se detectaron \\
\hline Otros a tener en cuenta & $\begin{array}{l}\text { Certificado Fitosanitario- } \\
\text { para presentar mínimo } 6 \\
\text { horas antes del embarque } \\
\text { ante la Dirección General } \\
\text { de Sanidad Vegetal } \\
\text { (Dirección de Lucha } \\
\text { Contra las Plagas). } \\
\text { Certificado de Origen- } \\
\text { emitido por la Cámara de } \\
\text { Exportadores de la } \\
\text { República Argentina. } \\
\text { Certificado Comercial } \\
\text { para exportar- tramitar } \\
\text { ante la Dirección General } \\
\text { de Producción y Fomento } \\
\text { Agrícola (Dirección de } \\
\text { Frutas y Hortalizas). }\end{array}$ & $\begin{array}{l}\text { Certificado } \\
\text { Fitosanitario del país } \\
\text { de origen- Instituto } \\
\text { Colombiano } \\
\text { Agropecuario ICA } \\
\text { Certificado de } \\
\text { Origen- Aduana } \\
\text { Visto bueno de } \\
\text { importación- Instituto } \\
\text { Nacional de } \\
\text { Vigilancia de } \\
\text { Medicamentos y } \\
\text { Alimentos INVIMA }\end{array}$ \\
\hline
\end{tabular}

Tabla 14: Información aduanera de nueces de nogal sin cáscara en Argentina y Colombia.

Fuente: elaboración propia. 


\begin{tabular}{|c|c|c|}
\hline NUECES DE PECÁN SIN CÁSCARA & Argentina & Colombia \\
\hline Posición arancelaria & 0802.90 .00 & 0802.90 .00 \\
\hline Derechos & $12 \%$ & $0 \%$ \\
\hline Reembolso & - & - \\
\hline Reintegro & $1,75 \%$ & - \\
\hline Impuesto al valor agregado (IVA) & - & $19 \%$ \\
\hline Barreras para arancelarias a considerar & no se detectaron & no se detectaron \\
\hline Otros a tener en cuenta & $\begin{array}{l}\text { Certificado Fitosanitario- } \\
\text { para presentar mínimo } 6 \\
\text { horas antes del embarque } \\
\text { ante la Dirección General } \\
\text { de Sanidad Vegetal } \\
\text { (Dirección de Lucha } \\
\text { Contra las Plagas). } \\
\text { Certificado de Origen- } \\
\text { emitido por la Cámara de } \\
\text { Exportadores de la } \\
\text { República Argentina. } \\
\text { Certificado Comercial } \\
\text { para exportar- tramitar } \\
\text { ante la Dirección General } \\
\text { de Producción y Fomento } \\
\text { Agrícola (Dirección de } \\
\text { Frutas y Hortalizas). }\end{array}$ & $\begin{array}{l}\text { Certificado } \\
\text { Fitosanitario del país } \\
\text { de origen- Instituto } \\
\text { Colombiano } \\
\text { Agropecuario ICA } \\
\text { Certificado de } \\
\text { Origen- Aduana } \\
\text { Visto bueno de } \\
\text { importación- Instituto } \\
\text { Nacional de } \\
\text { Vigilancia de } \\
\text { Medicamentos y } \\
\text { Alimentos INVIMA }\end{array}$ \\
\hline
\end{tabular}

Tabla 15: Información aduanera de nueces de pecán sin cáscara en Argentina y Colombia.

Fuente: elaboración propia. 


\begin{tabular}{|c|c|c|}
\hline PISTACHOS CON CÁSCARA & Argentina & Colombia \\
\hline Posición arancelaria & 0802.51 .00 & 0802.51 .00 \\
\hline Derechos & $12 \%$ & $0 \%$ \\
\hline Reembolso & - & - \\
\hline Reintegro & $1,75 \%$ & - \\
\hline Impuesto al valor agregado (IVA) & - & $19 \%$ \\
\hline Barreras para arancelarias a considerar & no se detectaron & no se detectaron \\
\hline Otros a tener en cuenta & $\begin{array}{l}\text { Certificado Fitosanitario- } \\
\text { para presentar mínimo } 6 \\
\text { horas antes del embarque } \\
\text { ante la Dirección General } \\
\text { de Sanidad Vegetal } \\
\text { (Dirección de Lucha } \\
\text { Contra las Plagas). } \\
\text { Certificado de Origen- } \\
\text { emitido por la Cámara de } \\
\text { Exportadores de la } \\
\text { República Argentina. } \\
\text { Certificado Comercial para } \\
\text { exportar- tramitar ante la } \\
\text { Dirección General de } \\
\text { Producción y Fomento } \\
\text { Agrícola (Dirección de } \\
\text { Frutas y Hortalizas). }\end{array}$ & $\begin{array}{l}\text { Certificado } \\
\text { Fitosanitario del país } \\
\text { de origen- Instituto } \\
\text { Colombiano } \\
\text { Agropecuario ICA } \\
\text { Certificado de } \\
\text { Origen- Aduana } \\
\text { Visto bueno de } \\
\text { importación- Instituto } \\
\text { Nacional de } \\
\text { Vigilancia de } \\
\text { Medicamentos y } \\
\text { Alimentos INVIMA }\end{array}$ \\
\hline
\end{tabular}

Tabla 16: Información aduanera de pistachos con cáscara en Argentina y Colombia.

Fuente: elaboración propia.

Para el recupero de IVA por la exportación realizada desde Argentina, el exportador debe estar inscripto en el IVA y solicitar el recupero ante la AFIP mediante el programa 
aplicativo "IVA- SOLICITUD DE REINTEGRO DEL IMPUESTO FACTURADO". Una vez admitida la solicitud, la AFIP debe expedir la comunicación del pago dentro de los 15 días hábiles.

\subsubsection{Territorio aduanero}

En Argentina, no constituyen territorio aduanero el mar territorial argentino y los ríos internacionales, las áreas francas, los exclaves, los espacios aéreos y el lecho y subsuelos submarinos nacionales ${ }^{71}$. Para este proyecto se tiene previsto realizar la exportación desde el puerto de Buenos Aires, que constituye territorio aduanero general, zona primaria aduanera.

Por otra parte, en Colombia ${ }^{72}$, el territorio aduanero nacional incluye todo el territorio, incluyendo los ríos y mares nacionales. El puerto de Cartagena, donde se realizará la importación, corresponde entonces al territorio aduanero nacional colombiano.

\subsubsection{Sujetos aduaneros}

Para llevar a cabo la exportación de frutos secos desde Argentina, la AFIP ${ }^{73}$ establece que intervienen los siguientes sujetos aduaneros: La Dirección General de Aduanas, los despachantes de aduanas y los agentes de transporte aduanero (ATA).

En Colombia, al momento de la importación de la mercadería interviene ${ }^{74}$ : la DIAN, el agente de carga internacional, el transportador internacional, el depósito o zona franca y el puerto o aeropuerto (según sea el modo elegido).

\footnotetext{
${ }^{71}$ Ley No. 22415. Recuperado de: http://servicios.infoleg.gob.ar/infoleglnternet/anexos/1500019999/16536/Ley22415 Titulo preliminar.htm Información tomada el 5 de febrero de 2020.

72 DIAN. Estatuto Aduanero. Recuperado de:

https://www.dian.gov.co/atencionciudadano/infoconsulta/Estatuto\%20Aduanero/Decreto 390 del 07de Marzo de 2016.p df Información tomada el 29 de enero de 2020.

${ }_{73}$ AFIP. Recuperado de: https://www.afip.gob.ar/genericos/guiavirtual/consultas_detalle.aspx?id=3818104 Información tomada el 28 de enero de 2020.

${ }^{74}$ BanRep. Recuperado de: https://www.banrep.gov.co/economia/sal deu x/pcebracs 1.pdf Información tomada el 28 de enero de 2020.
} 
3.1.4. Operatoria de intermediación

Para llevar a cabo la operación de intermediación ${ }^{75}$ que deriva de la exportación de los frutos secos a Colombia, es necesario adquirir la mercadería en el mercado interno argentino, que deberá oficializarse a través de una factura tipo A, emitida por el productor a la empresa intermediaria. La venta de la mercadería al cliente en el exterior, deberá instrumentarse mediante la emisión de una factura tipo E, que comprende "Operaciones de exportación".

3.1.5. Certificado Comercial para la exportación de frutos secos en Argentina

Para la emisión del Certificado Comercial, necesario para exportar las frutas secas, que otorga a Dirección General de Producción y Fomento Agrícola (Dirección de Frutas y Hortalizas) en Argentina, se deberá presentar una solicitud por cada especie y partida en los formularios provistos por la entidad, indicando la cantidad de bultos y kilogramos por especie y tipos, grados de selección y marcas, el procedimiento de inspección se realizará en el lugar de embarque. El Certificado Comercial tiene una validez de 15 días corridos.

\subsubsection{Certificado Fitosanitario}

En Argentina, el SENASA inspeccionará la fruta seca en el lugar de embarque con destino a la exportación, para esto, el despachante de aduanas designado deberá presentar el formulario provisto por la Dirección General de Sanidad Vegetal con una anticipación mínima de 6 horas antes de iniciado el embarque. Una vez inspeccionada la fruta seca y autorizado el embarque se otorgará el Certificado Fitosanitario correspondiente con una validez de 30 días.

En Colombia, el Certificado Fitosanitario para importación, es otorgado por el Instituto Colombiano Agropecuario ICA y debe obtenerse previo al embarque del producto. Tiene una validez de 90 días.

\footnotetext{
75 Instituto Argentino de Estudios Aduaneros. Recuperado de: http://www.iaea.org.ar/global/img/2010/09/PalavecinoMiguez.pdf Información tomada el 28 de enero de 2020.
} 


\subsubsection{Certificado de Origen}

El Certificado de Origen en Argentina se debe solicitar ante la Cámara de Exportadores de la República Argentina, que es la única autoridad competente avalada en Colombia para la expedición del documento. Dicho certificado ampara una sola operación de importación en Colombia y debe acompañar el resto de la documentación, en el momento de tramitar el despacho aduanero ${ }^{76}$.

Conforme al Acuerdo de Complementación Económica No. $59^{77}$ entre MERCOSUR y la CAN (ALADI) que involucra a los países de Argentina y de Colombia, para acceder a las preferencias arancelarias al momento de la importación en Colombia es necesario presentar el Certificado de Origen.

De acuerdo a dicho acuerdo, el criterio para la clasificación del origen de los frutos secos importados a Colombia, abarca a los productos del reino vegetal recolectados o cosechados en territorio argentino.

3.1.8. Visto Bueno de Importación para la importación de frutos secos en Colombia

En Colombia, para la obtención del Visto Bueno de Importación ante el Instituto Nacional de Vigilancia de Alimentos y Medicamentos INVIMA ${ }^{78}$, se debe estar previamente registrado como importador y diligenciar el formulario de intenciones de importación de alimentos (producto terminado).

\footnotetext{
${ }^{76}$ DIAN. Cartilla para el importador sobre la solicitud de trato arancelario. Recuperado de: https://www.dian.gov.co/aduanas/aspectecmercancias/origen/2.2.2\%20Cartilla\%20para\%20el\%20importador\%20sobre $\% 20$ la\%20solicitud\%20de\%20trato\%20arancelario\%20.pdf Información obtenida el 28 de enero de 2020.

77 ALADI. Acuerdo de Complementación Económica No. 59. Recuperado de: http://www2.aladi.org/biblioteca/publicaciones/aladi/acuerdos/ace/es/ace59/ACE 059 005.pdf Información tomada el 5 de enero de 2020.

78 Instituto Nacional de Vigilancia de Alimentos y Medicamentos INVIMA. Recuperado de:

https://www.invima.gov.co/documents/20143/349821/pautasdiligenciamientodevistosbuenosdeimportacionfinal.pdf/f9f8e05b -0a43-2aed-13e3-120fe09a23ef Información tomada el 6 de enero de 2020.
} 
3.1.9. Métodos de valoración aduanera

Tanto Colombia como Argentina, se rigen por los seis métodos de valoración aduanera aplicables a las mercaderías tratados en los artículos 1 al 7 del Acuerdo sobre Valoración de la $\mathrm{OMC}^{79}$ :

1. Métodos de Valor de Transacción de las Mercancías Importadas

2. Métodos de Valor de Transacción de Mercancías Idénticas

3. Métodos de Valor de Transacción de Mercancías Similares

4. Método Deductivo

5. Método del Valor Reconstruido

6. Método del Último Recurso

Al momento del embarque en Argentina y para poder aplicar posteriormente en Colombia el método 1 de valoración aduanera, es requisito que se cumplan las siguientes condiciones: prueba de venta, puede ser una factura o contrato; la misma no debe tener restricciones a la cesión o utilización, el precio declarado no debe estar sujeto a condiciones adicionales; se debe disponer de información suficiente a efectos de ajuste y no puede existir vinculación entre el comprador y vendedor.

Para la operación aduanera de importación de frutos secos en Colombia, se espera que la Aduana aplique el método 1 a través de la factura comercial que acompaña el embarque.

Para el proyecto que nos compete, el régimen de importación aplicable en Colombia es el de una importación definitiva para el consumo, la misma exige el pago de los derechos e impuestos causados por la importación. Bajo este régimen se declarará la importación de los frutos secos, ya que no existe el compromiso de devolver la mercadería fuera del territorio aduanero nacional.

3.2. Régimen bancario para cobros y pagos internacionales

79 OMC. Valoración en Aduana. Recuperado de: https://www.wto.org/spanish/tratop s/cusval s/cusval info s.htm Información tomada el 2 de febrero de 2020. 
El Banco Central de la República Argentina (BCRA) $)^{80}$ es el organismo rector del sistema financiero en la Argentina, se encarga, entre otras cosas, de la gestión de actividades inherentes a la emisión e interpretación de las normas de comercio exterior y de cambios, y a la administración, análisis y seguimiento de los movimientos de capitales y otras operaciones cambiarias, así como de las operaciones de cobros y pagos de comercio exterior, a fin de asegurar el cumplimiento de la política cambiaria.

El Banco de la República de Colombia ${ }^{81}$ es la autoridad monetaria, cambiaria y crediticia, le corresponde estudiar y adoptar las medidas monetarias, crediticias y cambiarias para regular la circulación monetaria y en general la liquidez del mercado financiero y el normal funcionamiento de los pagos internos y externos de la economía.

\subsubsection{Formas cobros y pagos internacionales}

En Argentina, los tres instrumentos de cobro internacional aplicables para la exportación de frutos secos son: carta de crédito o crédito documentario, cobranza y orden de pago.

El Banco de la República de Colombia ${ }^{82}$ establece que el pago de una importación de bienes, en este caso, de frutos secos, puede efectuarse en divisas, mediante el uso de tarjetas de crédito, en moneda legal o mediante cheque en moneda legal para el cobro por ventanilla a nombre del proveedor en el exterior.

En coherencia a lo anterior, las formas de cobros/pagos viables para la exportación/importación de frutos secos de Argentina a Colombia son: carta de crédito, cobranza documentaria y órdenes de pago.

\footnotetext{
${ }^{80}$ Banco Central de la República Argentina. BCRA. Recuperado de: http://www.bcra.gov.ar/Institucional/Estructura Detalle.asp?Nombre=Gerencia\%20Principal\%20de\%20Exterior\%20y\%20Ca mbios\&PrevPage=Estruc Información tomada el 29 de enero de 2020.

81 Banco de la República de Colombia. Recuperado de: https://www.banrep.gov.co/es/toma-decisiones Información tomada el 29 de enero de 2020.

82 BanRep. Recuperado de: https://www.banrep.gov.co/node/35560 Información tomada el 6 de enero de 2020.
} 
3.2.2. Bancos argentinos con corresponsalía en el exterior

En continuación se exponen los bancos autorizados para operar en comercio exterior en Argentina, los bancos intermediarios en dólares estadounidenses, ya que la operación de exportación se llevará a cabo en esta moneda y los bancos avalados para operar en comercio exterior en Colombia:

\begin{tabular}{|l|l|l|}
\hline $\begin{array}{c}\text { Banco en Argentina con } \\
\text { aval para operar en } \\
\text { comercio exterior }\end{array}$ & $\begin{array}{c}\text { Banco intermediario en } \\
\text { dólares estadounidenses } \\
\text { en el exterior }\end{array}$ & $\begin{array}{r}\text { Banco en Colombia con } \\
\text { aval para operar en } \\
\text { comercio exterior }\end{array}$ \\
\hline BBVA Argentina & Standard Chartered Bank & BBVA Colombia \\
\hline Santander Río & Standard Chartered Bank & Bancolombia \\
\hline Banco Galicia & Citibank & Banco de Bogotá \\
\hline Banco Macro & Standard Chartered Bank & Banco Agrario \\
\hline Banco de la Nación Argentina & Standard Chartered Bank & Banco Popular \\
\hline
\end{tabular}

Tabla 17: Bancos autorizados para operar en comercio exterior en Argentina y en Colombia.

Fuente: elaboración propia basada en datos de referencia ${ }^{83}$

3.2.3. Financiamiento y tipo de cambio

Para la compra de los frutos secos a los proveedores en Argentina, se podrá acceder a las líneas de financiamiento del Ministerio de la Producción Argentino ${ }^{84}$ : Pre y Post financiamiento de exportación de bienes, Forfaiting y apoyo a PYMES.

\footnotetext{
83 Bancos argentinos con aval para operar en el exterior. BBVA Argentina: https://www.bbva.com.ar/personas/productos/comex.html Santander Río: https://www.santander.com.ar/banco/online/empresas/comercio-exterior Banco Galicia: http://comex.bancogalicia.com/novedades/comercio-exterior Banco Macro: https://www.macro.com.ar/empresas/comex/servicios Banco de la Nación: https://www.bna.com.ar/Empresas/Pymes/Webcomex Información tomada el 28 de enero de 2020

84 Ministerio de Producción Argentino. Financiamiento. Recuperado de: https://www.argentina.gob.ar/produccion/financiamiento Información tomada el 7 de febrero de 2020.
} 
La AFIP ${ }^{85}$ establece que las operaciones en moneda extranjera se convertirán al tipo de cambio Comprador para las operaciones de Exportación, conforme a la cotización del Banco de la Nación Argentina al cierre del día en que se concrete la operación y de acuerdo a las normas y disposiciones que, en materia de cambios rijan en esa oportunidad.

En Colombia, la Tasa de Cambio Representativa del Mercado- TRM $^{86}$ es fijada por la Superintendencia Financiera de Colombia y es la usada para las operaciones de importación en el país.

\subsection{Transporte internacional de carga}

En el comercio internacional las operaciones de transporte cumplen un papel fundamental. La prueba de esta afirmación se basa en que un importante porcentaje del costo de cualquier producto comercializado actualmente en el mercado corresponde a esta operación ${ }^{87}$.

Es necesario evaluar todas las alternativas de transporte disponibles desde Argentina a Colombia, con el fin de contar con la información suficiente para la toma de decisiones que repercutan en el éxito de la operación.

3.3.1. Empacado y envasado de frutos secos para la exportación

En la resolución 1352-1967 en lo referente a frutos secos, el Servicio Nacional de Sanidad y Calidad Agroalimentaria SENASA ${ }^{88}$ establece que el empaque se debe hacer en las provincias donde hayan sido producidos, no se deben hacer mezclas de frutas secas de distintas cosechas o provincias. Para la mercancía destinada a exportación,

\footnotetext{
${ }^{85}$ AFIP. Impositiva Aduana Seguridad Social. Recuperado de: https://www.afip.gob.ar/genericos/guiavirtual/consultas detalle.aspx?id=753054 Información tomada el 1 de febrero de 2020.

${ }^{86}$ Superintendencia Financiera de Colombia. Recuperado de: https://www.superfinanciera.gov.co/publicacion/60819 Información tomada el 2 de febrero de 2020.

${ }^{87}$ Campana, E. (2001). El desafío de exportar: una visión clara y renovadora de las herramientas básicas para conquistar los mercados internacionales.(c.8 pp.165) Macchi: Buenos Aires

88 SENASA. Recuperado de: http://www.senasa.gob.ar/normativas/resolucion-1352-1967-senasa-servicio-nacional-desanidad-y-calidad-agroalimentaria Información tomada el 12 de enero de 2020. Anexo.
} 
puede ubicarse la indicación equivalente que se utilice en el país destino, en este caso es Colombia.

El embalaje de frutas secas a granel para exportación puede ser de cualquier material, cumpliendo con los siguientes requisitos: nuevo, seco, limpio, resistente y sin olor.

\subsubsection{Transporte marítimo}

Argentina tiene acceso directo al océano Atlántico y a los ríos internacionales Paraná y Uruguay, característica que define sus operaciones en el transporte marítimo internacional de carga. Los principales puertos marítimos argentinos son: Buenos Aires, Bahía Blanca, Quequén, Rosario y Santa Fe.

Colombia tiene acceso directo a los océanos Atlántico y Pacífico. Los principales puertos marítimos internacionales colombianos están ubicados en: Barranquilla, Santa Marta, Cartagena y Buenaventura.

Las navieras que prestan el servicio de ruta marítima para la exportación de frutos secos de Argentina a Colombia son: 


\begin{tabular}{|c|c|c|c|c|}
\hline $\begin{array}{l}\text { Agente } \\
\text { comercial }\end{array}$ & $\begin{array}{l}\text { Puerto de } \\
\text { embarque }\end{array}$ & $\begin{array}{c}\text { Puerto de } \\
\text { desembarque }\end{array}$ & Conexiones & $\begin{array}{l}\text { Tiempo en } \\
\text { tránsito }\end{array}$ \\
\hline Cma- Cgm & Buenos Aires & Cartagena & Itajai, Brasil & 22 días \\
\hline $\begin{array}{l}\text { Mahe Neutral } \\
\text { Shipping }\end{array}$ & Buenos Aires & Cartagena & Directo & 28 días \\
\hline $\begin{array}{l}\text { Mediterran } \\
\text { Shipping } \\
\text { Services }\end{array}$ & Buenos Aires & Cartagena & Directo & 21 días \\
\hline $\begin{array}{l}\text { Mediterran } \\
\text { Shipping } \\
\text { Services }\end{array}$ & Buenos Aires & Buenaventura & Directo & 29 días \\
\hline $\begin{array}{l}\text { Happag Lloyd } \\
\text { Arg. }\end{array}$ & Buenos Aires & Cartagena & Directo & 20 días \\
\hline
\end{tabular}

Tabla 18: Empresas navieras que cubren la ruta Argentina- Colombia.

Fuente: elaboración propia basada en datos de referencia ${ }^{89}$

3.3.2.1. Características de carga marítima habitual para frutos secos

Para el transporte marítimo internacional de frutos secos, se recomienda una humedad relativa del $65 \%$, una temperatura de $20^{\circ} \mathrm{C}$ y que la mercadería vaya protegida de la luz. Dadas las condiciones mencionadas anteriormente, se utilizan contenedores refrigerados, en unidades de 40 pies o de 20 pies que aseguren una mayor calidad del producto.

Generalmente los bultos con la mercadería van agrupados en pallets, para facilitar su manipuleo en el embarque y desembarque.

\footnotetext{
${ }^{89}$ Agentes navieros internacionales. Cma- Cmg: https://www.cma-cgm.com/ebusiness/schedules, Mahe Neutral Shipping: https://www.mahe.com.col, Mediterran Shipping Services: https://www.msc.com/search-schedules?link=5aa05d1c-953d4453-bead-0e337ccba332, Hapag Lloyd Arg: https://www.hapag-lloyd.com/en/online-business/schedules/interactiveschedule.html?sn=BUENOS+AIRES\&sl=ARBUE\&sp=\&en=CARTAGENA+\%28COLOMBIA\%29\&el=COCTG\&ep=\&exportH aulage=MH\&importHaulage=MH\&departureDate=2020-01-11\&weeksAfterStart=4\&reefer=N Información tomada el 11 de enero de 2020.
} 
Para el arribo de la mercadería en territorio colombiano, la ley dispone que el uso de depósitos fiscales aduaneros puede prorrogarse hasta por 30 días calendario previo al proceso de desaduanamiento.

\subsubsection{Transporte aéreo}

Argentina cuenta con 24 aeropuertos internacionales, según información de la Terminal de Cargas Argentina (TCA $)^{90}$ cinco aeropuertos internacionales registran operaciones de exportación: Aeroparque Jorge Newbery y Aeropuerto Internacional Ministro Pistarini, en Buenos Aires; Aeropuerto Internacional de Córdoba, en Córdoba; Aeropuerto Internacional de Mar del Plata, en Mar del Plata: Aeropuerto Internacional de Mendoza, en Mendoza y Aeropuerto Internacional de Tucumán, en Tucumán.

Colombia cuenta con 14 aeropuertos internacionales, los que registran operaciones de importación de mercadería internacional son: Aeropuerto Internacional El Dorado, En Bogotá; Aeropuerto Internacional Alfonso Bonilla Aragón, en Cali; Aeropuerto Internacional José María Córdova; en Medellín y Aeropuerto Ernesto Cortissoz, en Barranquilla.

Las rutas de transporte aéreo vigentes y directas para el transporte de frutos secos entre Argentina y Colombia, parten del Aeropuerto Internacional Ministro Pistarini, de Buenos Aires, arribando en el Aeropuerto Internacional El Dorado, en Bogotá.

La Terminal de Cargas Argentina (TCA) es la unidad de negocio que brinda servicios de almacenamiento y logística integral a los agentes de comercio exterior que exportan por vía aérea desde el Aeropuerto Internacional Ministro Pistarini. La Terminal Cargas Argentina tiene una superficie de $60.000 \mathrm{~m}^{2}$ y cuenta con las características operativas necesarias para el manipuleo de frutos secos palletizados para exportación.

La terminal de carga en Colombia del Aeropuerto Internacional El Dorado ${ }^{91}$ comprende $50.000 \mathrm{~m}^{2}$ en zonas de consolidación y transferencia con 214 muelles de embarque y

\footnotetext{
90 Terminal de Cargas Argentina TCA. Recuperado de: http://www.tca.aero/nosotros Información tomada el 6 de febrero de 2020.

91 Aeropuerto Internacional El Dorado. Recuperado de: https://eldorado.aero/aeropuerto/terminales/terminales-carga/ Información tomada el 1 de febrero de 2020.
} 
desembarque en el lado tierra. Cuenta con las características operativas necesarias para el manipuleo de frutos secos palletizados para importación.

Las aerolíneas que proveen el servicio de transporte de carga internacional desde Buenos Aires a Bogotá son las siguientes:

\begin{tabular}{|c|c|c|c|c|}
\hline Aerolínea & $\begin{array}{c}\text { Aeropuerto } \\
\text { origen }\end{array}$ & $\begin{array}{c}\text { Aeropuerto } \\
\text { destino }\end{array}$ & Conexiones & $\begin{array}{l}\text { Tiempo de } \\
\text { vuelo }\end{array}$ \\
\hline Avianca Cargo & $\begin{array}{l}\text { Ministro } \\
\text { Pistarini, Buenos } \\
\text { Aires }\end{array}$ & $\begin{array}{l}\text { El Dorado, } \\
\text { Bogotá }\end{array}$ & ninguna & $6: 20$ horas \\
\hline $\begin{array}{l}\text { Aerolíneas } \\
\text { Argentinas } \\
\text { Cargo }\end{array}$ & $\begin{array}{l}\text { Ministro } \\
\text { Pistarini, Buenos } \\
\text { Aires }\end{array}$ & $\begin{array}{l}\text { El Dorado, } \\
\text { Bogotá }\end{array}$ & ninguna & $6: 45$ horas \\
\hline
\end{tabular}

Tabla 19: Aerolíneas que cubren la ruta Argentina- Colombia.

Fuente: elaboración propia basada en datos de referencia ${ }^{92}$

Para esta exportación, el proceso de carga abarca desde el ingreso de la mercancía al aeropuerto, hasta la carga en el avión, incluyendo toda la tramitación aduanera necesaria. Para la carga y descarga de los frutos secos de la aeronave, se utilizan ULD tipo pallets, que permiten manipular la mercadería con mayor facilidad.

Para el arribo de la mercadería en territorio colombiano, la ley dispone que el uso de depósitos fiscales aduaneros puede prorrogarse hasta por 30 días calendario previo al proceso de desaduanamiento.

\subsubsection{Transporte terrestre}

La red vial argentina posee $436.825 \mathrm{kms}$ de carreteras. Está conformada por una red troncal de rutas nacionales que vincula a las principales ciudades del país y una red

\footnotetext{
92 Aerolíneas de carga internacional. Avianca Cargo: www.aviancacargo.com Aerolíneas Argentinas Cargo: www.cargo.aerolineas.com.ar Información tomada el 1 de febrero de 2020.
} 
secundaria compuesta por las rutas provinciales ${ }^{93}$, aspecto importante para la coordinación del transporte interno de la mercadería.

La red vial de Colombia posee 206.700 kms de carreteras y está compuesta por las troncales, las transversales, y accesos a capitales de departamentos, la misma cuenta con poca infraestructura, según el Instituto Nacional de Vías Invías ${ }^{94}$ solo el $13,61 \%$ de la red vial primaria está en excelentes condiciones.

Actualmente no existen operadores de transporte internacional que cubran la ruta Argentina- Colombia vía terrestre.

Las condiciones geográficas de la región sudamericana y los 6.795 kms en línea recta que separan las capitales de Argentina y Colombia, dificultan la logística de transporte terrestre.

Al consultar con varios operadores logísticos (Transpoarg, All Scand Cargo, Latinamerican Cargo $^{95}$ ) que prestan servicios de transporte internacional entre países sudamericanos, se mostraron incapaces de coordinar el envío de la mercadería por este medio hasta Colombia.

\subsubsection{Transporte marítimo desde Chile}

Dada la cercanía de la provincia de San Juan, donde se adquirirán los pistachos y las nueces de nogal para la exportación, con la provincia de Mendoza, donde se encuentra uno de los pasos fronterizos Argentina- Chile, otra alternativa a considerar es hacer el envío de la mercadería por vía terrestre desde San Juan y Entre Ríos a la provincia de Mendoza, pasando por el Paso Internacional Los Libertadores hasta llegar a territorio chileno y embarcar la mercadería en el puerto de Valparaíso, con destino a la ciudad de Cartagena, Colombia.

\footnotetext{
93 Asociación Argentina de Carreteras. Recuperado de: http://www.aacarreteras.org.ar/index.php Información tomada el 12 de marzo de 2020.

${ }_{94}^{9}$ INVIAS. Instituto Nacional de Vías. Recuperado de: www.invias.gov.co Información tomada el 12 de marzo de 2020

95 Empresas de transporte terrestre. Transpoarg: http://www.transpoarg.com/\#home, All Scand Cargo: https://www.allscandcargo.com/transporte-terrestre/, Latin American Cargo: https://www.latinamericancargo.com/es/ Información tomada el 28 de enero de 2020.
} 
Las navieras consultadas sobre la ruta Chile- Colombia, embarcan desde otros puertos chilenos lejanos de Mendoza (Arica, Lirquen, San Antonio, Iquique) y desembarcan únicamente en el puerto de Buenaventura, en Colombia, lo que extendería en tiempos la operativa de exportación, poniendo en riesgo la conservación de la mercadería.

La única empresa naviera que presta el servicio Valparaíso Cartagena (Mahe Neutral Shipping Ltda) ${ }^{96}$ hace una escala en la ciudad de Manzanillo, Panamá, con un tiempo de tránsito total de 27 días.

\subsection{Seguros internacionales}

Para la exportación de frutos secos desde Argentina a Colombia intervienen los siguientes tipos de seguros:

- Seguro Terrestre dentro del territorio de la República Argentina

Cubre el tránsito de la mercadería desde el depósito ubicado en las ciudades productoras de las 3 especies de frutos secos: nuez nogal y pistacho en San Juan, y nuez pecán en Entre Ríos, hasta la ciudad de Buenos Aires.

Existen 2 tipos de cobertura: básica y todo riesgo.

Dado que la exportación se hará en condición FOB, el seguro terrestre deberá ser asumido por el exportador.

La prima promedio del mercado para este seguro es del $0,7 \%$ valor $\mathrm{EXW}^{97}$.

- Seguro de Transporte Internacional:

Cubre el tránsito marítimo de la mercadería desde el puerto de Buenos Aires, Argentina, hasta el puerto en la ciudad de Cartagena, Colombia.

Entre los principales riesgos que cubre este seguro están: pérdida total, contribución de la avería gruesa, avería particular en casos de naufragio y robo parcial del contenido. Este seguro en condición FOB queda a cargo del importador.

La prima promedio del mercado para este seguro es del $0,5 \%$ del valor $\mathrm{FOB}^{98}$.

\footnotetext{
${ }^{96}$ Mahe Neutral Shipping. Recuperado de: https://www.mahe.com.co/ Información tomada el 28 de enero de 2020.

97 Información basada en cotización enviada por la empresa La Segunda. Recuperado de:

https://www.lasegunda.com.ar/home Tomada el 2 de febrero de 2020.

98 Información basada en cotización enviada por la empresa Coex. Recuperado de:

https://www.grupocoex.co/ Tomada el 2 de febrero de 2020.
} 
- Seguro de cambio de divisas:

Dado que las operaciones se harán en dólares estadounidenses, este seguro sirve para fijar un precio fijo de venta, sin importar las fluctuaciones de la moneda.

Existen 2 tipos de seguro de cambio o forward: delivery forward-con entrega y non delivery forward- sin entrega. La idea del forward es acordar un tipo de cambio futuro para la venta de USD entre exportador e importador.

La gestión de este seguro queda a cargo del exportador con el banco que se elija para realizar la operación de cobro ${ }^{99}$.

3.5. Documentación de embarque habitual para la exportación de frutos secos

\subsubsection{Documentación requerida para exportar desde Argentina(fuente)}

Para la exportación de los frutos secos desde Argentina a Colombia son necesarios los siguientes documentos ${ }^{100}$ :

- Conocimiento de embarque.

- Factura comercial.

- Certificado Fitosanitario.

- Certificado comercial.

- Certificado de origen.

- Packing list.

\subsubsection{Documentación requerida para importar en Colombia}

Para la importación de los frutos secos provenientes de Argentina en Colombia, son necesarios los siguientes documentos ${ }^{101}$ :

- Manifiesto de carga de importación.

\footnotetext{
${ }^{99}$ BBVA Colombia. Recuperado de: https://www.bbva.com.co/ Información tomada el 2 de febrero de 2020. 100 Ministerio de Desarrollo Económico. Guía para la primera exportación. Recuperado de: https://www.buenosaires.gob.ar/sites/gcaba/files/guia para la primera exportacion.pdf Información tomada el 12 de marzo de 2020.

${ }^{101}$ Mincomercio. Ministerio de Comercio, Industria y Turismo. Recuperado de: http://www.mincit.gov.co/estudios-economicos/como-importar-a-colombia Información tomada el 12 de marzo de 2020.
} 
- Conocimiento de embarque.

- Factura comercial.

- Registro de importación radicado ante el Ministerio de Comercio.

- Certificado Fitosanitario- se debe presentar ante el Instituto Colombiano Agropecuario ICA.

- Visto Bueno de Importación- se debe tramitar en formularios provistos por el Instituto Nacional de Vigilancia de Medicamentos y Alimentos INVIMA.

De acuerdo a lo establecido por la DIAN ${ }^{102}$ los documentos de viaje que acompañan la importación de frutos secos deben ser entregados a través de los Servicios Informáticos Electrónicos 12 horas antes de la llegada del buque. El proceso de desaduanamiento de la importación comprende: la declaración aduanera de importación, que se debe presentar junto con los documentos soporte referidos anteriormente y el aforo, pago y retiro de las mercancías.

\subsection{Conclusiones}

El análisis de la gestión operativa de comercio exterior necesaria para lograr la exportación de frutos secos de Argentina a Colombia, permite tener un panorama claro de los requisitos y trámites obligatorios en ambos países.

De acuerdo a lo investigado, no existen barreras para-arancelarias para la importación de frutos secos en Colombia, pero sí hay que cumplir con una serie de documentos exigidos para la salida de la mercadería en Argentina y su posterior ingreso, en Colombia.

La evaluación de los distintos modos de transporte internacional vigentes para realizar la operación de exportación, permite tomar decisiones en base a los tiempos y costos de cada opción viable.

Los seguros internacionales son requerimientos indispensables para concretar con éxito la operatoria de exportación a Colombia y sus respectivas primas deberán ser tenidas en cuenta al momento de establecer los costos totales del proyecto.

\footnotetext{
102 Dirección de Impuestos y Aduanas Nacionales de Colombia DIAN. Nueva Regulación Aduanera. Recuperado de: https://www.dian.gov.co/aduanas/Documents/Nueva\%20Regulaci\%C3\%B3n\%20Aduanera\%20en\%20Colombia.pdf Información tomada el 2 de febrero de 2020.
} 


\section{PARÁMETROS DEL PROYECTO DE EXPORTACIÓN DE FRUTOS SECOS}

Conforme a lo expuesto en el capítulo tres de este proyecto, son varios los requisitos necesarios para lograr el flujo de la mercadería entre ambos países.

En este capítulo se definirán los lineamientos específicos para el proceso operativo de la exportación de nueces de nogal, nueces de pecán y pistachos desde Argentina a Colombia.

\subsection{Transacción comercial doméstica}

La cantidad establecida de frutos secos para exportar desde Argentina a Colombia es de 200 kilos por especie, para un embarque total de 600 kilos de mercadería. Se espera mantener una frecuencia de embarque trimestral durante el primer año del proyecto.

La compra de los frutos secos en el mercado doméstico se hará a tres a empresas productoras y/o comercializadoras distintas, en sus respectivas provincias de procedencia de origen:

La nuez nogal sin cáscara será comprada a un comercializador en la provincia de San Juan, su razón social es Montilla Héctor Aníbal persona física monotributista y CUIT 2021358260-8, a un precio de USD 13,33 por kilo, para un total de USD 2.666 por los 200 kilos. Las nueces serán cosecha 2020 y la mercadería será entregada en 8 bolsas de plástico de 25 kilos cada una empacadas al vacío.

La nuez pecán sin cáscara será comprada a una productora y comercializadora en la provincia de Entre Ríos, su razón social es Los Pecanes Sociedad Anónima y CUIT 3071456264-5, a un precio de USD 11 por kilo, para un total de USD 2.200 los 200 kilos. Las nueces serán cosecha 2020 y la mercadería será entregada en 8 bolsas de plástico de 25 kilos cada una empacadas al vacío. 
El pistacho con cáscara será comprado a una productora y comercializadora en la provincia de San Juan, su razón social es Frutos del Sol Sociedad Anónima y CUIT 3067324839-6 a un precio de USD 10,40 por kilo para un total de USD 2.080 los 200 kilos. El pistacho será cosecha 2020 y la mercadería será entregada en 8 bolsas de plástico de 25 kilos cada una empacadas al vacío.

El exportador de este proyecto es una nueva empresa que será constituida como sociedad comercial con domicilio en Argentina, bajo la razón social de "GEVEN Frutos Secos Sociedad Anónima", la misma será inscrita ante el Registro de Sociedades Comerciales. Posterior a esto y para que la empresa pueda oficiar como exportadora será registrada ante la AFIP como "operador de comercio exterior", anexando la documentación correspondiente.

El importador de este proyecto será la empresa FRUTCOM SAS con domicilio en Colombia, la cual figura en el Directorio de Importadores del año 2019 de la DIAN ${ }^{103}$, cuyo objeto social es el comercio al por mayor de productos alimenticios. Esta empresa será la encargada del fraccionamiento de las frutas secas y su posterior comercialización en destino.

\subsection{Gestión aduanera en origen y destino}

En Argentina, se contratará a un despachante de aduanas que se encargará de toda la coordinación para realizar la operación de exportación a Colombia. Sus honorarios son del $1 \%$ del valor FOB.

Los gastos administrativos para el canal verde son del orden de USD \$50, para los canales naranja y rojo USD 150.

El despachante de aduanas también será quien genere y presente la declaración de exportación ante la AFIP a través del sistema informático SIM. Este trámite tiene un costo de USD 10 por declaración.

103 Directorio de importadores 2019. DIAN. Recuperado de: https://www.dian.gov.co/dian/cifras/Paginas/EstadisticasComEx.aspx Información tomada el 25 de febrero de 2020. 
Para las tres especies de frutos secos elegidas, los derechos de exportación en Argentina corresponden al $12 \%$ y el reintegro es del $1,75 \%$.

\begin{tabular}{|l|l|l|l|}
\hline \multicolumn{1}{|c|}{ Producto } & \multicolumn{1}{|c|}{$\begin{array}{c}\text { Posición } \\
\text { arancelaria }\end{array}$} & \multicolumn{1}{|c|}{$\begin{array}{c}\text { Gravamen } \\
\text { aduanero }\end{array}$} & \multicolumn{1}{|c|}{ Reintegros } \\
\hline $\begin{array}{l}\text { Nueces de nogal sin } \\
\text { cáscara }\end{array}$ & 0802.32 .00 .00 & $12 \%$ & $1,75 \%$ \\
\hline $\begin{array}{l}\text { Nueces de pecán sin } \\
\text { cáscara }\end{array}$ & 0802.90 .00 & $12 \%$ & $1,75 \%$ \\
\hline $\begin{array}{l}\text { Pistachos con } \\
\text { cáscara }\end{array}$ & 0802.51 .00 & $12 \%$ & $1,75 \%$ \\
\hline
\end{tabular}

Tabla 20: Información arancelaria de nueces de nogal sin cáscara, nueces de pecán sin cáscara y pistachos con cáscara en Argentina.

Fuente: elaboración propia basada en datos de referencia ${ }^{104}$

En Colombia, de acuerdo a lo expuesto en el "Acuerdo de Complementación Económica No. 59 suscrito entre Argentina, Brasil, Paraguay y Uruguay, estados partes del Mercosur, y Colombia, Ecuador y Venezuela, países miembros de la CAN ${ }^{105 *}$, para la importación de las tres especies de frutos secos elegidas aplica arancel del $0 \%$.

En Colombia, con el ingreso de la mercadería, el agenciamiento aduanero de importación que incluye recinto del contenedor, planilla de traslado estimado, transmisión electrónica, gastos operativos e inspecciones físicas tiene un costo de USD 360.

Los costos del almacenamiento de la mercadería en Colombia en el depósito fiscal tienen un promedio de USD 90 por día.

\footnotetext{
${ }^{104}$ Servicios en línea MUISCA. DIAN. Recuperado de:

https://muisca.dian.gov.co/WebArancel/DefConsultaGeneralNomenclaturas.faces Información tomada el 15 de febrero de 2020.

105 Acuerdo de Complementación Económica No. 59. Mercosur. Preferencias otorgadas a Argentina. Recuperado de: http://www2.aladi.org/biblioteca/publicaciones/aladi/acuerdos/ace/es/ace59/ACE 059 Anexo 002 Apen 001 Co.pdf Información tomada el 15 de febrero de 2020.
} 


\begin{tabular}{|l|l|}
\hline \multicolumn{1}{|c|}{ Concepto } & \\
\hline Despachante de aduanas en origen & $1 \%$ valor FOB \\
\hline Gastos administrativos en origen & USD 50 \\
\hline Declaración de exportación- SIM en origen & USD 10 \\
\hline Derechos de exportación & $12 \%$ \\
\hline Reintegros & $1,75 \%$ \\
\hline Arancel de importación & $0 \%$ \\
\hline Agenciamiento aduanero de importación & USD 360 \\
\hline Depósito fiscal en destino & USD 90 \\
\hline
\end{tabular}

Tabla 21: Costos aduaneros en Argentina y en Colombia.

Fuente: elaboración propia.

4.3. Gestión bancaria en origen y destino

Debido a la poca confianza existente entre exportador e importador, la forma de cobro/pago elegida para este proyecto es mediante Carta de Crédito Internacional.

El cobro/pago se hará a través del Banco BBVA Argentina y su correspondiente corresponsalía en Colombia, BBVA Colombia. Dado que la operación será realizada en dólares estadounidenses, el banco intermediario en el exterior es Standard Chartered Bank, con sede en Londres, Reino Unido.

Para la fijación de comisiones expuestas a continuación en origen y en destino, se toma como promedio un valor FOB de USD 8.000 para cada uno de los embarques trimestrales programados: 
Comisiones vigentes para cartas de crédito de exportaciones argentinas (por caso)

\begin{tabular}{|l|l|l|}
\hline Concepto & $\%$ & USD \\
\hline Notificación & 0.125 & 100 \\
\hline Utilización & 0.125 & 100 \\
\hline Confirmación & 0.125 & 100 \\
\hline Transferencia beneficiario & 0.125 & 100 \\
\hline Confirmación nuevo período & 0.125 & 100 \\
\hline Modificación & - & 70 \\
\hline Télex SWIFT & - & 10 \\
\hline Transferencia de crédito doc. a bancos locales & - & 40 \\
\hline
\end{tabular}

Tabla 22: Comisiones de comercio exterior en Argentina.

Fuente: BBVA Argentina ${ }^{106}$

En Argentina, según el "Texto ordenado de las normas sobre comercio exterior y cambios $^{-107}$ los cobros de las exportaciones de frutos secos oficializadas a partir del 02.09.19 deberán liquidarse en el mercado de cambios en los 180 días corridos desde la fecha de cumplido el embarque otorgado por la Aduana argentina. El exportador deberá seleccionar una entidad bancaria para que realice el "Seguimiento de las negociaciones de divisas por las exportaciones de bienes" (SECOEXPO).

Una vez recibida la Carta de Crédito del banco BBVA Argentina, el banco BBVA Colombia procederá a avisar, confirmar y pagar por la importación de acuerdo a las instrucciones del documento con lo pactado entre exportador e importador.

\footnotetext{
106 BBVA Argentina. Tabla de cargos y comisiones en pesos y moneda extranjera. Recuperado de: https://www.bbva.com.ar/tablas/comijurmicro.pdf Información tomada el 14 de febrero de 2020.

107 Banco Central de la República Argentina. BCRA. Recuperado de: http://www.bcra.gov.ar/Pdfs/Texord/t-excbio.pdf Información tomada el 29 de enero de 2020.
} 


\begin{tabular}{|c|c|c|}
\hline Concepto & $\%$ & USD \\
\hline Apertura- Comisión primeros 90 días & 1,000 & 130 \\
\hline Apertura- Mensaje SWIFT & & 35 \\
\hline $\begin{array}{l}\text { Modificación- Aumento de valor (sobre el vr del } \\
\text { incremento) }\end{array}$ & 1,000 & 100 \\
\hline Modificación- Mensaje SWIFT o validez & & 25 \\
\hline $\begin{array}{l}\text { Modificación- Prórroga vigencia o validez (mes o } \\
\text { fracción) }\end{array}$ & 0,400 & 100 \\
\hline $\begin{array}{l}\text { Modificación- Prórroga sobre saldo pendiente sin } \\
\text { utilizar (mes o fracción) }\end{array}$ & 0,400 & 60 \\
\hline Modificación- Otros conceptos & & 60 \\
\hline Utilización- A partir de la segunda utilización & & 50 \\
\hline Utilización- Mensaje SWIFT & & 25 \\
\hline Utilización- Discrepancias o validez expirada & & 50 \\
\hline Utilización- Pago diferido (mes o fracción) & 0,350 & 50 \\
\hline Utilización- Por aceptación (mes o fracción) & 0,400 & 60 \\
\hline Devolución documentos (Courier) & & 50 \\
\hline Comisión de Sustitución Banco de la República & 10 & 0 \\
\hline Comisión Administrativa & & $\$ 5.300$ \\
\hline
\end{tabular}

Tabla 23: Comisiones de comercio exterior en Colombia.

Fuente: BBVA Colombia 108

\footnotetext{
108 BBVA Colombia. Comisiones de comercio exterior. Recuperado de: https://www.bbva.com.co/content/dam/publicweb/colombia/documents/home/prefooter/tarifas/DO-03-Comisiones-Comercio-Exterior.pdf Información tomada el 14 de febrero de 2020.
} 
4.4. Tránsito doméstico de la mercadería desde origen hasta el puerto de exportación

En sintonía con lo expuesto en el subcapítulo anterior, la mercadería proviene de dos provincias argentinas distintas, por lo tanto, se hace necesaria la coordinación de dos tránsitos domésticos hasta el depósito fiscal DEFISA ${ }^{109}$, ubicado en zona portuaria de la ciudad de Buenos Aires, donde se consolidará la carga previo al embarque.

El primer tránsito parte de la provincia de San Juan, llevando consigo los 200 kilos de nueces de nogal sin cáscara y 200 kilos de pistachos con cáscara, para un total de 400 kilos de mercadería, hasta el depósito fiscal DEFISA, en Buenos Aires. Los frutos secos van empacados al vacío y refrigerados en 16 bolsas de $25 \mathrm{~kg}$ cada una, el precio de este flete es USD 1.000.

El segundo tránsito parte de la provincia de Entre Ríos, llevando consigo 200 kilos de nueces de pecán sin cáscara hasta el depósito fiscal DEFISA, en Buenos Aires. Los frutos secos van empacados al vacío y refrigerados en 8 bolsas de $25 \mathrm{~kg}$ cada una, el precio de este flete es USD 500.

De acuerdo a lo anterior, el precio total del flete interno terrestre para llevar la mercadería hasta el puerto de Buenos Aires es de USD 1.500

\subsection{Acondicionamiento y consolidación de la carga para la exportación}

Una vez que la mercadería llegue al depósito fiscal DEFISA, ubicado en la zona portuaria de la ciudad de Buenos Aires, la carga será acondicionada, consolidada y almacenada con un precio de USD 90 por día.

Cada una de las bolsas de las 3 especies de frutos secos provenientes de las provincias productoras tienen medidas de $60 \times 50 \times 15 \mathrm{~cm}$, son de material plástico y van empacadas al vacío listas para la exportación, conforme a la normativa del SENASA.

109 DEFISA. Depósito fiscal. Recuperado de: http://www.defisa.com.ar/index.php Información tomada el 1 de marzo de 2020. 
llustración 1: Modelo de bolsa para el empacado de los frutos secos.

Fuente: elaboración propia.

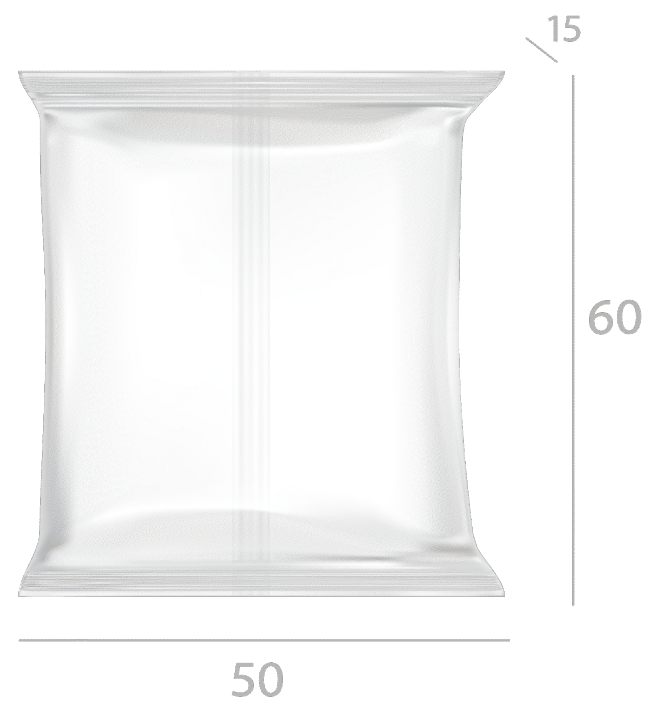

Las 24 bolsas con mercadería, serán ubicadas sobre un pallet americano de $120 \times 100$ $\mathrm{cm}$, siendo 4 bolsas por piso, para un total de 6 pisos. Este tipo de pallet soporta una carga de hasta $1.200 \mathrm{~kg}$, siendo suficiente para el transporte de la mercadería que no supera los $600 \mathrm{~kg}$.

Ilustración 2: Simulación de la ubicación de la carga en el pallet.

Fuente: elaboración propia.

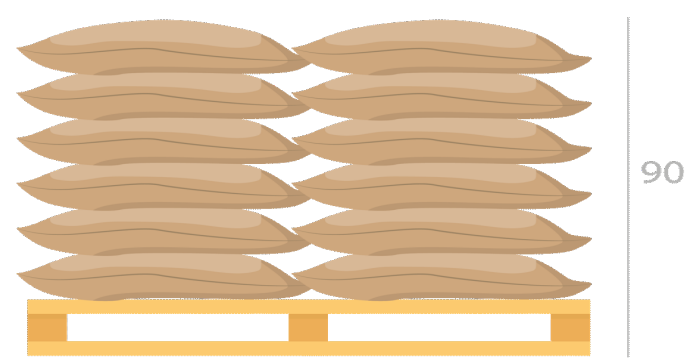

El pallet será transportado en un contenedor compartido o LCL refrigerado de 20 pies. 
Será utilizado un film termocontraíble y zunchos plásticos en el embalaje para proteger la mercadería de la humedad externa y los roedores.

El valor del manipuleo de la mercancía en origen es de USD 300 y en destino de USD 200.

\subsection{Transporte internacional de la carga}

Los dos medios de transporte internacional disponibles para este proyecto exportador de frutos secos son el marítimo y el aéreo.

Para el cálculo del flete marítimo desde el Puerto de Buenos Aires, en Argentina, hasta el Puerto de Cartagena, en Colombia, se tomó el flete del tránsito internacional de la mercadería en un contenedor LCL o compartido refrigerado de 20 pies. La carga será consolidada en 1 pallet americano, ocupando un volumen de $1,08 \mathrm{~m}^{3}$. El valor del flete es de USD 460 con la empresa naviera Happag Lloyd.

Para el proceso de contenerización, la mercancía va agrupada en bolsas de plástico empacadas al vacío de $25 \mathrm{~kg}$ cada una, ajustada con zunchos plásticos y embalada con un film termocontraíble sobre un pallet americano que será ubicado en el contenedor compartido refrigerado LCL de 20 pies, ocupando un volumen de 1,08 $\mathrm{m}^{3}$.

La mercancía será maniobrada y cargada en el contenedor compartiendo espacio con el resto de la carga, finalmente el contenedor será trasladado hasta el muelle del puerto listo para el tránsito internacional hasta Colombia.

Para el cálculo del flete aéreo desde el Aeropuerto Internacional Ministro Pistarini, en Buenos Aires, hasta el Aeropuerto Internacional El Dorado, en Bogotá, se tomó la tarifa vigente para 2020 de la empresa Aerolíneas Argentinas Cargo.

El peso volumen de la mercadería por unidad es de $7,5 \mathrm{~kg}$ y el peso real es de $25 \mathrm{~kg}$, por ende se tomó el peso real como "peso tarifario" para aplicar el precio del tránsito internacional en kilos.

$+500 \mathrm{~kg}=$ USD $1,30 \times \mathrm{kg}$ 
Este valor corresponde al tramo EZEIZA-BOGOTÁ de carga a temperatura controlada, más USD 65 de otros gastos fijos. Dicha ruta es operada por una aeronave de fuselaje angosto de la empresa Aerolíneas Argentinas.

A continuación una tabla con el costo del flete y características de cada opción:

\begin{tabular}{|l|l|l|l|l|l|}
\hline \multicolumn{1}{|c|}{$\begin{array}{c}\text { Medio de } \\
\text { transporte }\end{array}$} & \multicolumn{1}{|c|}{ Origen } & \multicolumn{1}{|c|}{ Destino } & $\begin{array}{l}\text { Tiempo en } \\
\text { tránsito }\end{array}$ & Peso & Costo flete \\
\hline Marítimo & $\begin{array}{l}\text { Puerto de } \\
\text { Buenos Aires }\end{array}$ & $\begin{array}{l}\text { Puerto de } \\
\text { Cartagena }\end{array}$ & 21 días & 600 kilos & USD 460 \\
\hline Aéreo & $\begin{array}{l}\text { Aeropuerto } \\
\text { Internacional } \\
\text { Ministro } \\
\text { Pistarini, } \\
\text { Buenos Aires }\end{array}$ & $\begin{array}{l}\text { Aeropuerto } \\
\text { Internacional } \\
\text { El Dorado, } \\
\text { Bogotá }\end{array}$ & $\begin{array}{l}6 \text { horas y } \\
20 \text { minutos }\end{array}$ & 600 kilos & USD 845 \\
\hline
\end{tabular}

Tabla 24: Características de los fletes disponibles.

Fuente: elaboración propia.

Debido a que el proyecto se llevará a cabo con una antelación suficiente, el producto a exportar tiene un alto grado de conservación y por conveniencia de costos, el medio de transporte elegido para ejecutar la operatoria de exportación es el marítimo.

4.7. Documentación de embarque con las certificaciones necesarias en origen y destino

4.7.1. Documentación de embarque y certificaciones requeridas para exportar desde Argentina

Para cumplir con los requisitos exigidos para exportar frutos secos desde Argentina, se debe presentar la siguiente documentación:

- Conocimiento de embarque: será emitido por la empresa naviera Happag Lloyd, elegida para realizar el transporte internacional marítimo desde el puerto de Buenos Aires, al puerto de Cartagena. 
Tiene un costo de USD 50.

- Factura comercial: será emitida por el exportador con el detalle de los tres frutos secos a exportar: nueces de nogal, nueces de pecán y pistachos y la cantidad por cada especie.

La AFIP exige que la letra de identificación en las facturas de exportación sea la "E".

- Certificado Fitosanitario/calidad comercial para exportaciones: será otorgado por el SENASA con una validez de 30 días.

Tiene un costo de USD 0,51.

- Certificado de Origen: será emitido por la Cámara de Exportadores de la República Argentina, tiene un validez de una operación de exportación.

Tiene un costo de USD 10.

- Packing list: será emitido por el exportador, con el detalle del contenido, peso bruto y neto de la mercadería y tipo de embalaje.

4.7.2. Documentos y certificaciones requeridas para importar en Colombia

Al llegar la mercadería a territorio aduanero colombiano, es necesario portar y tramitar la siguiente documentación:

- Manifiesto de carga de importación: será emitido por la naviera encargada del transporte marítimo internacional y será transmitido con 24 horas de anticipación al puerto de Cartagena.

- Conocimiento de Embarque: que acompaña el viaje desde el puerto de Buenos Aires, Argentina.

- Factura Comercial: que acompaña el viaje desde el puerto de Buenos Aires, Argentina.

- Registro de importación radicado ante el Ministerio de Comercio: se tramitará a través de la Ventanilla Única de Comercio Exterior- VUCE ante el Ministerio de Comercio, Industria y Turismo de Colombia.

Tiene un costo de USD 11,76

- Certificado Fitosanitario de Importación: se tramitará ante el Instituto Colombiano Agropecuario- ICA del Ministerio de Agricultura y Desarrollo Rural, tiene una validez de 90 días. 
Tiene un costo de USD 18

- Visto Bueno de Importación: se tramitará ante el Instituto Nacional de Vigilancia de Medicamentos y Alimentos INVIMA.

Tiene un costo de USD 4,38

\subsection{Costos}

Dado el carácter operativo de esta tesis, para la exposición de los costos solo se pondrá foco en el costeo de la gestión logística y no en la estrategia de precio internacional.

4.8.1. Cálculo de costos operativos de exportación

\begin{tabular}{|l|c|r|}
\hline Costos de exportación & $\%$ & \multicolumn{1}{c|}{ USD } \\
\hline Costo de la mercadería & & 6946,00 \\
\hline Fletes internos & & 1500,00 \\
\hline Seguro interno & $0,7 \%$ & 49,00 \\
\hline Certificaciones & & 11,00 \\
\hline Gastos aduaneros & & 450,00 \\
\hline Gastos fijos bancarios & & 500,00 \\
\hline Otros gastos & & 0,00 \\
\hline Total costos de exportación & $1,0 \%$ & 105,77 \\
\hline Comisión despachante de aduanas & $0,6 \%$ & 63,45 \\
\hline Gastos bancarios & & 169,22 \\
\hline Total gastos indirectos & & 9625,22 \\
\hline Costo total & $12,0 \%$ & 528,80 \\
\hline Derechos de exportación & $1,75 \%$ & 165,25 \\
\hline Reintegros a cobrar & $1,5 \%$ & 587,29 \\
\hline Impuesto a las ganancias & 10576,06 \\
\hline Valor FOB & & \\
\hline Tabla $25:$ Costos de la exporion & \\
\hline
\end{tabular}

Tabla 25: Costos de la exportación.

Fuente: Calculadora VUCE ${ }^{110}$

${ }^{110}$ Ventanilla Única de Comercio Exterior. VUCE. Recuperado de: http://calculadora.vuce.gob.ar/\#!/ Cálculo realizado el 1 de marzo de 2020. 
4.8.2. Cálculo de costos operativos de importación

\begin{tabular}{|l|l|l|}
\hline Costos de importación & \multicolumn{1}{|c|}{$\%$} & USD \\
\hline Valor FOB & & 10576,00 \\
\hline Flete internacional & & 460,00 \\
\hline Seguro internacional & $0,5 \%$ & 52,88 \\
\hline Valor CIF & $0,0 \%$ & 11088,88 \\
\hline Arancel de importación & $19,0 \%$ & 0,00 \\
\hline IVA & & 2106,89 \\
\hline Gastos aduaneros & & 650,00 \\
\hline Certificaciones & 34,00 \\
\hline Costos totales de importación & & 13879,77 \\
\hline
\end{tabular}

Tabla 26: Costos de la importación.

Fuente: elaboración propia.

\subsection{Conclusiones}

Los lineamientos específicos de la operatoria de exportación de nueces de nogal, nueces de pecán y pistachos desde Argentina a Colombia sirven como guía para llevar a cabo en un futuro cercano este proyecto exportador.

En el cálculo de los costos es importante resaltar el alto porcentaje del tránsito doméstico terrestre en Argentina en el costo total de la exportación, sin embargo este se ve compensado en el costo de la mercadería al ser adquiridos a productores directos en cada provincia de origen.

Los gastos aduaneros en Argentina son considerablemente más bajos que en Colombia.

La Carta de Crédito elegida para llevar a cabo el cobro/pago de la exportación es más costosa que otros medios de pago internacionales, pero brinda mayor seguridad para cada una de las partes involucradas en la operatoria.

La elección del medio marítimo como transporte internacional incrementa los tiempos de tránsito del proyecto, pero abarata los costos totales del mismo. 


\section{CONCLUSIONES FINALES}

El proyecto para la exportación de frutos secos al mercado internacional se llevó a cabo poniendo foco en la gestión operativa de comercio exterior.

El desarrollo de este proyecto corresponde a la gestión operativa para lograr el flujo de la mercadería entre ambos países y es complementaria con la tesis "Plan Estratégico de Marketing Internacional para una comercializadora de frutos secos", desarrollada por el maestrando Steven Cerpa.

Inicialmente se estudió de la producción argentina de frutos secos y su potencial exportador, después se identificaron los aspectos operativos relevantes para llevar a cabo la exportación y finalmente, se establecieron los lineamientos operativos específicos para la exportación de nueces de nogal, nueces de pecán y pistachos desde Argentina a Colombia.

La producción de frutos secos alrededor del mundo evidencia un incremento del $47 \%$ en comparación a 10 años atrás, según datos del International Nut \& Dried Fruit Council (INC), lo anterior va de la mano con el aumento del consumo, convirtiéndose en una gran oportunidad para los países que los cultivan.

Estados Unidos, lidera la producción mundial de frutos secos, seguido de Turquía y China.

De acuerdo a lo estudiado, Argentina se encuentra en proceso de desarrollo productivo con gran cantidad de hectáreas disponibles y en acondicionamiento para en un futuro próximo comenzar a cultivar y producir, esto demuestra que el país cuenta con potencial para convertirse en un referente de frutos secos a nivel regional.

La producción argentina de frutos secos está destinada principalmente a abastecer el mercado interno, con significativas oportunidades y poco desarrollo a la orientación exportadora. 
La nuez nogal, la nuez pecán y el pistacho fueron las tres especies elegidas para este proyecto, ya que gracias a sus volúmenes de importación y exportación, se dedujo que cuentan con producción suficiente para abastecer el mercado interno e internacional.

Las exportaciones de frutas secas o procesadas desde Argentina a Colombia, el país destino elegido para llevar a cabo este proyecto exportador, demuestran un gran aumento, pasando de 94 kilos de mercadería exportados en 2014 a 3.793 kilos en 2018, según datos del INDEC ${ }^{111}$.

Es importante resaltar el potencial productivo de frutos secos en Argentina y el constante crecimiento de la demanda del mercado colombiano, como una gran oportunidad para las exportaciones de este tipo de producto entre ambos países.

En Argentina, para las tres especies de frutos secos elegidas, los derechos de exportación corresponden al $12 \%$ y el reintegro es del $1,75 \%$.

Las preferencias arancelarias otorgadas por Colombia a Argentina en el marco del Acuerdo Económico No. 59 del MERCOSUR, permiten el ingreso de las tres especies de frutos secos elegidas a territorio aduanero colombiano con un arancel de $0 \%$, para lograrlo es requisito que el embarque vaya acompañado del Certificado de Origen.

El régimen bancario aplicado a las operaciones de comercio exterior en Argentina y Colombia presenta sus particularidades en cada país.

En el país origen los tres instrumentos avalados para el cobro de una exportación son: carta de crédito, cobranza y orden de pago. En el país destino, el pago de la importación puede hacerse también en divisas, mediante el uso de tarjetas de crédito, en moneda legal o mediante cheque en moneda legal para el cobro por ventanilla a nombre del proveedor en el exterior.

Este aspecto fue tenido en cuenta al momento de elegir la Carta de Crédito como instrumento de cobro y pago internacional para este proyecto.

111 Instituto Nacional de Estadísticas INDEC. Recuperado de: https://opex.indec.gov.ar/index.php?pagina=mapa dinamico Información tomada el 26 de febrero de 2020. 
La evaluación de los distintos medios de transporte disponibles entre ambos países permitió elegir la opción marítima por conveniencia de costos y tiempo en tránsito (20 días), teniendo en cuenta la alta conservación del producto y la frecuencia semanal de salidas desde el puerto de Buenos Aires hasta el puerto de Cartagena.

El impacto económico de la logística integrada es del 34\% en el precio internacional del producto a exportar, un valor relativamente alto si se tiene en cuenta que lo comprende principalmente el costo del flete interno, que equivale a un $41 \%$ y los gastos bancarios un $16 \%$ del total.

Se espera que en la medida que se vaya incrementando la confianza entre exportador e importador sea posible amortizar costos de transporte mediante la compra de mayor cantidad de mercadería y hacer uso de un medio de pago internacional más económico.

La evaluación de la operatoria de exportación de frutos secos desde Argentina a Colombia descrita en esta tesis, permite exponer la viabilidad de este proyecto mostrando un panorama favorecedor, dadas las características del producto que inciden en la demanda actual por parte del país destino, las preferencias arancelarias otorgadas por Colombia y la oferta en Argentina con miras a consolidar su potencial productivo en un futuro próximo.

A continuación se expone la secuencia temporal de la operatoria de exportación propuesta para el primer embarque:

Cronograma del primer embarque para el proyecto exportador
TAREAS A REALIZAR/DURACIóN
Compra de la mercadería en Argentina
Gestión aduanera en origen
Transporte interno de la mercadería hasta el puerto
Acondicionamiento y consolidación de la carga
Gestión bancaria en origen
Preparación documentación de embarque
Tránsito internacional hasta Colombia
Llegada de la mercadería
Gestión aduanera en destino
Liberación del producto para su comercialización

Esquema 20: Cronograma del primer embarque para el proyecto exportador.

Fuente: elaboración propia. 
Para la continuidad del proyecto se espera mantener una frecuencia de embarques trimestral durante el primer año, conforme a lo expuesto en el siguiente diagrama:

Cronograma de los embarques para el primer año del proyecto exportador

FRECUENCIA DE EMBARQUES/DURACIÓN

Embarque 1

Embarque 2

Embarque 3

Embarque 4 \begin{tabular}{|l|l|l|l|l|l|l|l|l|l|l|}
\hline MES 1 & MES 2 & MES 3 & MES 4 & MES 5 & MES 6 & MES 7 & MES 8 & MES 9 & MES 10 & MES 11 \\
MES 12
\end{tabular}

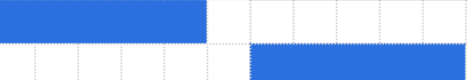

Esquema 21: Cronograma de los embarques para el primer año del proyecto exportador.

Fuente: elaboración propia.

A modo de cierre, el propósito de este proyecto exportador de frutos secos es concretar la operatoria en un futuro próximo, como parte de un negocio internacional en la creación de una empresa born global. 


\section{6. ÍNDICE BIBLIOGRÁFICO}

6.1. Bibliografía formal- libros

Berman, J. (2014). Gestión del Comercio Exterior. Buenos Aires: Edicon

Bradley, F. Y Haydeé, C. (2006). Marketing Internacional 5a edición. Pearson: Buenos Aires.

Campana. E. (2001). El desafío de exportar: una visión clara y renovadora de las herramientas básicas para conquistar los mercados internacionales. Macchi: Buenos Aires

Cignacco, B. (2004). Fundamentos de comercialización internacional para pymes. Buenos Aires: Macchi

Kotler, P. Y Amstrong, G. (2017). Marketing 17a edición. Ciudad de México: Pearson Educación

Sainz de Vicuña Ancin, J.M. (2016). Plan de internacionalización de la pyme en la práctica. Madrid: Esic

6.2. Fuentes de Internet

Avianca Cargo. Recuperado de: www.aviancacargo.com Información tomada el 1 de febrero de 2020.

Aerolíneas Argentinas Cargo. Recuperado de: www.cargo.aerolineas.com.ar Información tomada el 1 de febrero de 2020. 
Aeropuerto Internacional El Dorado. Recuperado de:

https://eldorado.aero/aeropuerto/terminales/terminales-carga/ Información tomada el 1 de febrero de 2020.

AFIP. Resolución General No. 2570/2009. Recuperado de: http://biblioteca.afip.gob.ar/dcp/REAG01002570 20090227 Información tomada el 27 de enero de 2020.

Agentes navieros internacionales. Cma- Cmg. Recuperado de: https://www.cmacgm.com/ebusiness/schedules. Información tomada el 28 de enero de 2020.

ALADI. Acuerdo de Complementación Económica No. 59. Recuperado de: http://www2.aladi.org/biblioteca/publicaciones/aladi/acuerdos/ace/es/ace59/ACE 0 59 005.pdf Información tomada el 5 de enero de 2020.

Alimentos Argentinos. Recuperado de: http://www.alimentosargentinos.gob.ar/HomeAlimentos/Frutas\%20secas/frutaseca s/productos/Almendras 2003/Almendras.htm Información tomada el 20 de octubre de 2019.

All Scand Cargo. Recuperado de: https://www.allscandcargo.com/transporte-terrestre/ Información tomada el 28 de enero de 2020.

Asociación Argentina de Carreteras. Recuperado de: http://www.aacarreteras.org.ar/index.php Información tomada el 12 de marzo de 2020.

Banco de la Nación: https://www.bna.com.ar/Empresas/Pymes/Webcomex Información tomada el 28 de enero de 2020.

Banco de la República de Colombia. Recuperado de: https://www.banrep.gov.co/economia/sal deu x/pcebracs 1.pdf Información tomada el 28 de enero de 2020. 
Banco Galicia. Comercio exterior Recuperado de:

http://comex.bancogalicia.com/novedades/comercio-exterior Información tomada el 28 de enero de 2020.

Banco Macro: https://www.macro.com.ar/empresas/comex/servicios Información tomada el 28 de enero de 2020.

BBVA Argentina. Comercio exterior. Recuperado de:

https://www.bbva.com.ar/personas/productos/comex.html Información tomada el 28 de enero de 2020.

BBVA Colombia. Comisiones de comercio exterior. Recuperado de:

https://www.bbva.com.co/content/dam/publicweb/colombia/documents/home/prefooter/tarifas/DO-03-Comisiones-ComercioExterior.pdf Información tomada el 14 de febrero de 2020.

BCRA. Banco Central de la República Argentina. Recuperado de: http://www.bcra.gov.ar/Institucional/Estructura Detalle.asp?Nombre=Gerencia\%20 Principal\%20de\%20Exterior\%20y\%20Cambios\&PrevPage=Estruc Información tomada el 29 de enero de 2020.

Botanical Online. Recuperado de: https://www.botanical-online.com/cultivo/nueces-brasilcomo-plantar-cuidados Información tomada el 30 de noviembre de 2019

Coex. Recuperado de: https://www.grupocoex.co/ Tomada el 2 de febrero de 2020.

Código Alimentario Argentino, Capítulo XI. Recuperado de https://www.argentina.gob.ar/anmat/codigoalimentario Información tomada el 20 de agosto de 2019.

DEFISA. Depósito fiscal. Recuperado de: http://www.defisa.com.ar/index.php Información tomada el 1 de marzo de 2020. 
DIAN. Instituto Nacional de Estadística. Recuperado de:

https://www.dian.gov.co/atencionciudadano/infoconsulta/Estatuto\%20Aduanero/D ecreto 390 del 07de Marzo de 2016.pdf Información tomada el 29 de enero de 2020.

FAO. Organización de las Naciones Unidas para la Alimentación y la Agricultura.

Recuperado de: http://www.fao.org/faostat/es/\#data/QC Información tomada el 26 de octubre de 2019.

GOV.CO. Portal Único del Estado Colombiano. Recuperado de:

https://www.gov.co/servicios-y-tramites/t328 Información tomada el 27 de enero de 2020.

Hapag Lloyd Arg. Recuperado de:

https://www.hapag-Iloyd.com/en/online-business/schedules/interactiveschedule.html?sn=BUENOS+AIRES\&sl=ARBUE\&sp=\&en=CARTAGENA+\%28CO

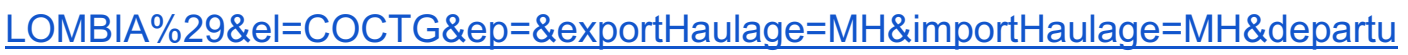
reDate=2020-01-11\&weeksAfterStart=4\&reefer=N Información tomada el 11 de enero de 2020.

INC. International Nut \& Dried Fruit Council Recuperado de:

https://www. nutfruit.org/industry/technical-resources?category=statisticalyearbooks Información tomada el 16 de octubre de 2019.

INDEC. Instituto Nacional de Estadística y Censos. Recuperado de: https://comex.indec.gov.ar/search/exports/2017/Y/8021100,8021200/ Información tomada el 18 de noviembre de 2019.

Infoagro. Recuperado de: https://www.infoagro.com/frutas/frutos secos/castano.htm Información tomada el 21 de noviembre de 2019.

Instituto Argentino de Estudios Aduaneros. Recuperado de: http://www.iaea.org.ar/global/img/2010/09/PalavecinoMiguez.pdf Información tomada el 28 de enero de 2020. 
INTA. Instituto Nacional de Tecnología Agropecuaria. Recuperado de:https://inta.gob.ar/noticias/almendros-las-ventajas-que-ofrece-este-cultivo-ylos-cuidados-que-requiere Información tomada el 23 de octubre de 2019.

INVIAS. Instituto Nacional de Vías. Recuperado de: www.invias.gov.co Información tomada el 12 de marzo de 2020

INVIMA. Instituto Nacional de Vigilancia de Alimentos y Medicamentos. Recuperado de: https://www.invima.gov.co/documents/20143/349821/pautasdiligenciamientodevist osbuenosdeimportacionfinal.pdf/f9f8e05b-0a43-2aed-13e3-120fe09a23ef Información tomada el 6 de enero de 2020.

La Segunda. Recuperado de: https://www.lasegunda.com.ar/home Información tomada el 2 de febrero de 2020.

Latin American Cargo. Recuperado de: https://www.latinamericancargo.com/es/ Información tomada el 28 de enero de 2020.

Ley No. 22415. Recuperado de:

http://servicios.infoleg.gob.ar/infolegInternet/anexos/1500019999/16536/Ley22415 Titulo preliminar.htm Información tomada el 5 de febrero de 2020.

Mahe Neutral Shipping. Recuperado de: https://www.mahe.com.co/Información tomada el 28 de enero de 2020.

Mediterran Shipping Services. Recuperado de: https://www.msc.com/searchschedules?link=5aa05d1c-953d-4453-bead-0e337ccba332 Información tomada el 28 de enero de 2020.

Mincomercio. Ministerio de Comercio, Industria y Turismo. Recuperado de: http://www.mincit.gov.co/estudios-economicos/como-importar-a-colombia Información tomada el 12 de marzo de 2020. 
Ministerio de Desarrollo Económico. Guía para la primera exportación. Recuperado de: https://www.buenosaires.gob.ar/sites/gcaba/files/guia para la primera exportacio $\underline{\text { n.pdf }}$

Información tomada el 12 de marzo de 2020.

Ministerio de Producción Argentino. Financiamiento. Recuperado de:

https://www.argentina.gob.ar/produccion/financiamiento Información tomada el 7 de febrero de 2020.

OMC. Organización Mundial del Comercio. Valoración en Aduana. Recuperado de: https://www.wto.org/spanish/tratop s/cusval s/cusval info s.htm Información tomada el 2 de febrero de 2020.

Relevamiento Nacional de Frutos Secos. Universidad de Cuyo:

https://app.powerbi.com/view?r=eyJrljoiNWRkYmFIZjgtNzU4ZS00ZGQzLWJkNzYt NjgyNDI3NWM3YTU3liwidCI6ImZmNjdkZTc3LWRjN2YtNGRIZC1iNjA3LWM4MDh kNWI4Zjk2MilsImMiOjR9 Información tomada el 17 de octubre de 2019.

Santander Río. Comercio exterior. Recuperado de:

https://www.santander.com.ar/banco/online/empresas/comercio-exterior Información tomada el 28 de enero de 2020.

SENASA. Servicio Nacional de Sanidad y Calidad Agroalimentaria. Recuperado de: http://www.senasa.gob.ar/normativas/resolucion-1352-1967-senasa-servicionacional-de-sanidad-y-calidad-agroalimentaria Información tomada el 12 de enero de 2020. Anexo.

Servicios en línea MUISCA. DIAN. Recuperado de: https://muisca.dian.gov.co/WebArancel/DefConsultaGeneralNomenclaturas.faces Información tomada el 15 de febrero de 2020.

Superintendencia Financiera de Colombia. Recuperado de: https://www.superfinanciera.gov.co/publicacion/60819 Información tomada el 2 de febrero de 2020. 
TCA. Terminal de Cargas Argentina. Recuperado de: http://www.tca.aero/nosotros Información tomada el 6 de febrero de 2020.

Transpoarg. Recuperado de: http://www.transpoarg.com/\#home Información tomada el 28 de enero de 2020.

VUCE. Ventanilla Única de Comercio Exterior. Recuperado de: http://calculadora.vuce.gob.ar/\#!/ Cálculo realizado el 1 de marzo de 2020. 
"Declaro bajo juramento que esta tesis fue elaborada por mí, que no utilicé ningún otro material que no haya dado a conocer en las referencias y que no utilicé frases o párrafos de otros autores y que este trabajo de tesis nunca ha sido presentado ante un comité de evaluación de tesis y que no transgrede derechos de terceros."

Gheraldine Mancilla Toro.

Buenos Aires, 5 de marzo de 2020. 